\title{
Photothermal materials for efficient solar powered steam generation
}

\author{
Fenghua Liu ${ }^{1}$, Yijian Lai ${ }^{1}$, Binyuan Zhao $(\bowtie){ }^{1}$, Robert Bradley ${ }^{2,3}$, Weiping Wu $\left.(\bowtie)\right)^{4}$ \\ 1 State Key Laboratory of Metal Matrix Composites, School of Materials Science and Engineering, \\ Shanghai Jiao Tong University, Shanghai 200240, China \\ 2 Department of Materials, University of Oxford, Oxford, OX1 3PH, UK \\ 3 MatSurf Technology Ltd., Cumbria, CA10 1NW, UK \\ 4 Department of Electrical and Electronic Engineering, School of Mathematics, Computer Science and Engineering, \\ City, University of London, Northampton Square, London, EC1V 0HB, UK
}

(C) The Author(s) 2019. This article is published with open access at link.springer.com and journal.hep.com.cn

\begin{abstract}
Solar powered steam generation is an emerging area in the field of energy harvest and sustainable technologies. The nano-structured photothermal materials are able to harvest energy from the full solar spectrum and convert it to heat with high efficiency. Moreover, the materials and structures for heat management as well as the mass transportation are also brought to the forefront. Several groups have reported their materials and structures as solutions for high performance devices, a few creatively coupled other physical fields with solar energy to achieve even better results. This paper provides a systematic review on the recent developments in photothermal nanomaterial discovery, material selection, structural design and mass/heat management, as well as their applications in seawater desalination and fresh water production from waste water with free solar energy. It also discusses current technical challenges and likely future developments. This article will help to stimulate novel ideas and new designs for the photothermal materials, towards efficient, low cost practical solar-driven clean water production.
\end{abstract}

Keywords solar stream generation, plasmonics, porous carbon, photothermal materials, solar energy conversion efficiency, water vapor generation rate

\section{Introduction}

Currently, one-fifth of the world's population is facing

Received December 1, 2018; accepted February 19, 2019

E-mails: byzhao@sjtu.edu.cn (Zhao B),

Weiping.Wu@city.ac.uk (Wu W) scarcity in energy and clean water resources. Finding sufficient freshwater resources has become a top priority in the strategic plans of most governments, as it affects the potential for economic growth and social well-being of billions of people [1]. Naturally, sustainable saline water desalination becomes a principle means and effective way for many societies to secure fresh water, because the saline water accounts for $97 \%$ of the earth's water storage.

Usually, desalination processes can be categorized into two types: membrane processes and thermal processes. Membrane desalination processes include electro-dialysis (ED) [2], reverse electrodialysis (RED) [3], capacitive deionization [4], reverse osmosis (RO) [5,6], and membrane distillation [7]. Thermal desalination processes, based on phase change processes, include multi-stage flash distillation (MSF) [8], multi-effect distillation (MED) $[9,10]$, humidification dehumidification [11], and vapor compression distillation (VCD). Among these VCD desalination techniques, MSF, MED and RO are widely used at present [12]. In particular, high energy consumption is a critical factor that affects the economics of desalination. Therefore, it becomes imperative to find alternative clean sources of energy for desalination.

With the development of new materials in recent years, especially the nano-materials, such as plasmonic nanometal particles [13], graphene, graphene oxide, carbon nanotubes and porous carbon, solar distillation, this ancient technology has regained a new breakthrough development. In principle, it just like the typical solar distillation apparatus, sunlight is captured and converted to heat and then used to generate water vapor, which can subsequently be condensed to produce fresh water. Based on the knowledge gained from the new research, water evaporation occurs at the interface theory, solar-driven water evaporation can be realized efficiency and environmentally 
friendly assisted by these newly emerged photothermal materials $[14,15]$.

In the last few years, the research on utilizing photothermal materials for both solar water evaporation and solar distillation has attracted a fast growing interest. In particular, the solar distillation's features of zero $\mathrm{CO}_{2}$ emission, low energy consumption and high efficiency toward seawater desalination are very contemporarily appealing and relevant in the times of ongoing and ever worsening environment, clean energy shortage, and water scarcity.

Solar steam generation is a complicated physical process including energy absorption, heat transfer and mass transfer. How to realize the maximum absorption and conversion efficiency of solar energy is the critical core. This frontier review highlights impressive developments in material selection, thermal management and mass transfer. The applications of these new materials and structural designs in solar vapor generation are reviewed. The current challenges and future perspectives are discussed.

\section{Solar absorbing materials}

Solar energy is the input source to realize the water vapor generation, the primary condition as well. The solar spectrum ranges from 280 to $2500 \mathrm{~nm}$ [16], and most of the energy is composed of the visible light $(400-700 \mathrm{~nm}$, $45 \%)$ and the IR light (700-2500 nm, 52\%). In order to capture solar energy to the maximum extent, the photothermal materials are expected to absorb broadly within the entire solar spectrum. So far, nanoparticles and porous carbon-based materials are two kinds of materials suitable for solar water evaporation.

\subsection{Plasmonic nanometals}

Plasmon resonance is a well-known phenomenon in many metals. When the frequency of incident light matches the oscillation frequency of delocalized electrons in the metals, it triggers a collective excitation of the electrons, generating hot electrons. The hot electrons oscillate coherently with the incident electromagnetic field, resulting in heat generation by a Joule mechanism $[17,18]$. In 2016, Meng et al. discussed the effect and theory of plasmonic photocatalysis and plasmonic photo-thermocatalysis to convert solar energy to chemical energy [19].

The plasmonic effect of noble metal nanomaterials is wavelength specific and highly dependent on their shapes and sizes [20]. Gold distinguishes itself among its peers due to its high tunability of light adsorption within the solar spectrum, chemical stability, availability of rich synthesis methods, and nontoxicity. In 2010, Lukianova-Hleb et al. used short laser pulses to generate transient vapor nanobubbles around plasmonic nanoparticles. They studied the photothermal, mechanical, and optical properties of the bubbles and thought the mechanical and optical scattering properties of plasmonic nanobubble depended upon the nanoparticle surface and heat capacity, clusterization state, and the optical pulse length [21].

The performance of light-induced vapor generation with Au nanoparticles immersed in liquid was investigated by Fang et al. in 2013, as shown in Fig. 1 [22]. A nanometer scale envelope of vapor can be formed when the $\mathrm{Au}$ particles are illuminated with sufficient and resonant light, and a dramatic temperature jump was also observed. In 2013 and 2014, Halas's group pioneered Au nanoparticleenabled solar vapor generation which inspired wide research interest in solar water evaporation and beyond [22-25]. Solar illumination of broadly absorbing metal nanoparticles dispersed in a liquid produces vapor without the requirement of heating the fluid volume. The absorbed solar energy can direct primarily vaporization of water into steam.

To harvest a wide solar spectrum absorbing solar energy at a maximum extent, metal nanoparticles with a wide size distribution and/or various shapes are combined in some works. In 2017, Guo et al. studied the diameter effect (varied from 3 to $40 \mathrm{~nm}$ ) of gold nanoparticles on photothermal conversion for solar steam generation [26]. In order to further improve the water vapor conversion efficiency, the heat loss must be considered to reduce, while nanoparticles spread in water is not very suitable. People began to try to change the distribution of nanoparticles, prepare floating reaction layers as the solar absorbing and vapor generation layers, to reduce the heat lost to the bulk water. In 2014, Wang et al. fabricated a free-floating film of gold nanoparticles at the air-water interface in which the thermal energy is provided directly at the evaporative surface, leading to a fast and efficient evaporation [27]. After that, Liu et al. further produced free-standing films by depositing $\mathrm{Au}$ nanoparticles onto airlaid paper [28] and anodized aluminum oxide (AAO) $[29,30]$. Localized heating occurred only at the air-water interface, these floating films can lead to an improved water evaporation efficiency.

Given the inherently narrow absorption bandwidth of well-sorted Au nanoparticles, in 2015, Bae et al. developed flexible thin-film black Au membranes with multiscale structures of varying metallic nanoscale gaps $(0-200 \mathrm{~nm})$, which had an average absorption of $91 \%$ at $400-2500 \mathrm{~nm}$ and showed effective solar water evaporation [31]. In 2016, Tian et al. demonstrated the efficacy of an $\mathrm{Au}$ nanorod loaded biomaterial derived 3D aerogel for solar water evaporation [32]. To further expand the absorption of solar radiation, in 2016, Zhou et al. reported a plasmonic absorber through loading $\mathrm{Au}$ nanoparticles with random sizes and distributions into a nanoporous template (AAO) by a one-step deposition process with an average absorbance of $\sim 99 \%$ from $400 \mathrm{~nm}$ to $10 \mu \mathrm{m}$ [33].

To reduce the thermal radiation, in 2017, Zhou et al. fabricated spectrum-selective plasmonic absorbers with 
(a)

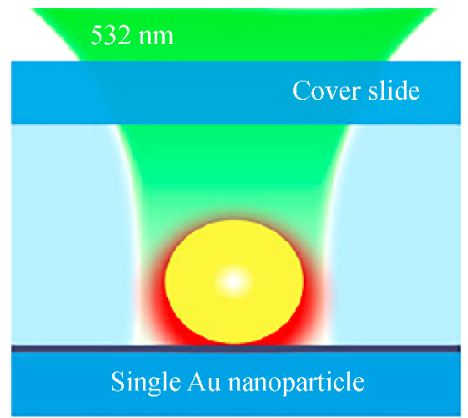

(c)

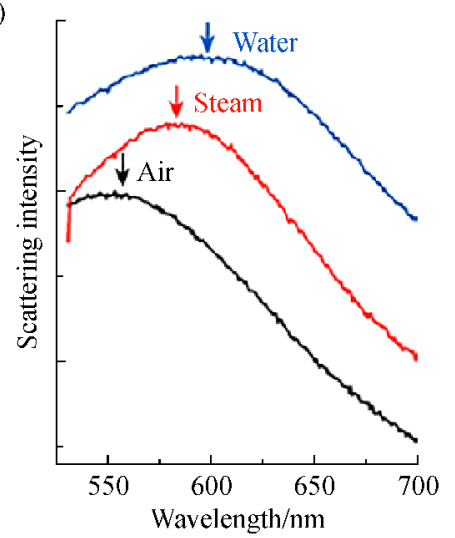

(b)
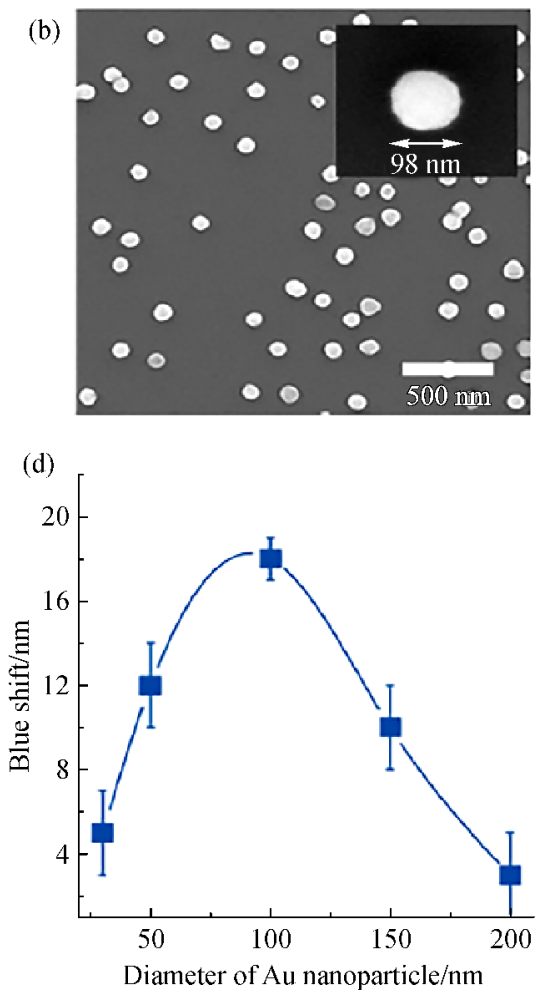

Fig. 1 (a) Schematic showing illumination and plasmonic heating of an individual Au nanoparticle on the transparent glass substrate floor of our fluidic microchamber; (b) Scanning electron microscope (SEM) images of a sample with a dense coverage of Au nanoparticles randomly distributed on the glass substrate and a typical nanoparticle (inset); (c) Scattering intensities of a single $100 \mathrm{~nm}$ diameter nanoparticle in air (black), water (blue), and an envelope of water vapor produced by laser illumination (red); (d) Dependence of nanobubble-induced localized surface plasmon resonance blueshift on Au nanoparticle diameter, with a maximum shift observed for a nanoparticle diameter of $100 \mathrm{~nm}$. Reprinted with permission from ref. [22]. Copyright 2013, American Chemical Society.

flexibly tuned bandwidth with Au nanoparticles. The plasmon hybridization of the close-packed gold nanoparticles can improve the absorption, and the optical cutoff effect of the gold-particle-assembly built nanotube can lead to the tunable absorption edge [34]. Liu et al. provided a theoretical analysis of the performances of the system based on first principle simulations, shows a broadband absorption $97 \%$ from 350 to $1450 \mathrm{~nm}$. A black layer was made by nanorods $(75 \mathrm{~nm})$ connected with nanospheres (18 $\mathrm{nm}$ diameter) on a filter paper and the thickness about $200 \mathrm{~nm}$, which reaches a solar thermal efficiency of $87 \%$ when exposed to an intensity of 2.3 sun, maintaining a stable efficiency of $90 \%$ at higher solar intensities [35].

Other plasmonic metal nanomaterials have also been investigated towards solar evaporation and distillation. In 2016, Zhou et al. demonstrated a plasmon-enhanced solar desalination device, fabricated by the self-assembly of aluminium nanoparticles into a three-dimensional porous membrane, as shown in Fig. 2. The porous plasmonic absorber can efficiently absorb a broad solar spectrum ( $>96 \%$ ) and focus the absorbed energy at the surface of the water to enable efficient $(\sim 90 \%)$ and effective desalination [36]. In 2017, Wang et al. fabricated silver nanoparticles (AgNPs) with different polyhedral morphology control (diameter: 48.7-411.9 nm) via a household microwave oven, which exhibited a good match to the solar spectrum in the UV to near infrared wavelength range [37]. In 2017, Fang et al. showed a device with Ag/ diatomite combined with a filter paper, an airlaid paper and a polystyrene foam which realized the evaporation rate at $1.39 \mathrm{~kg} \cdot \mathrm{m}^{-2} \cdot \mathrm{h}^{-1}$ under one-sun illumination [38]. In 2017 , researchers reported many other metal nanoparticles in the water vapor generation with solar energy, such as Pd NPs on wood membrane [39], depositing nanometer iridium film onto a porous anodic alumina template [40], and indium nanoparticles on paper [41].

\subsection{Nano carbon materials}

The carbon-based materials can absorb widely in the entire solar spectrum and the excited electrons relax to their ground state, releasing heat, due to the closely spaced energy levels of the loosely-held $\pi$ electrons. Carbon based-materials, including carbon black, carbon nanotubes (CNTs), graphene, graphene oxide (GO), reduced graphene oxide (rGO), porous carbon, etc. are among the most 
(a)

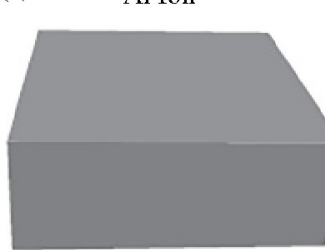

(d) (b)

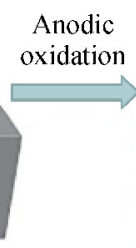

(e) (c) A1 NP/AAM

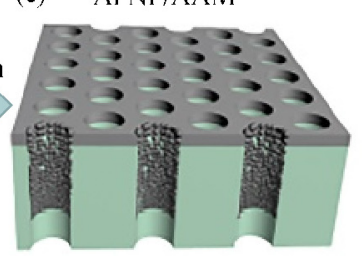

(f)
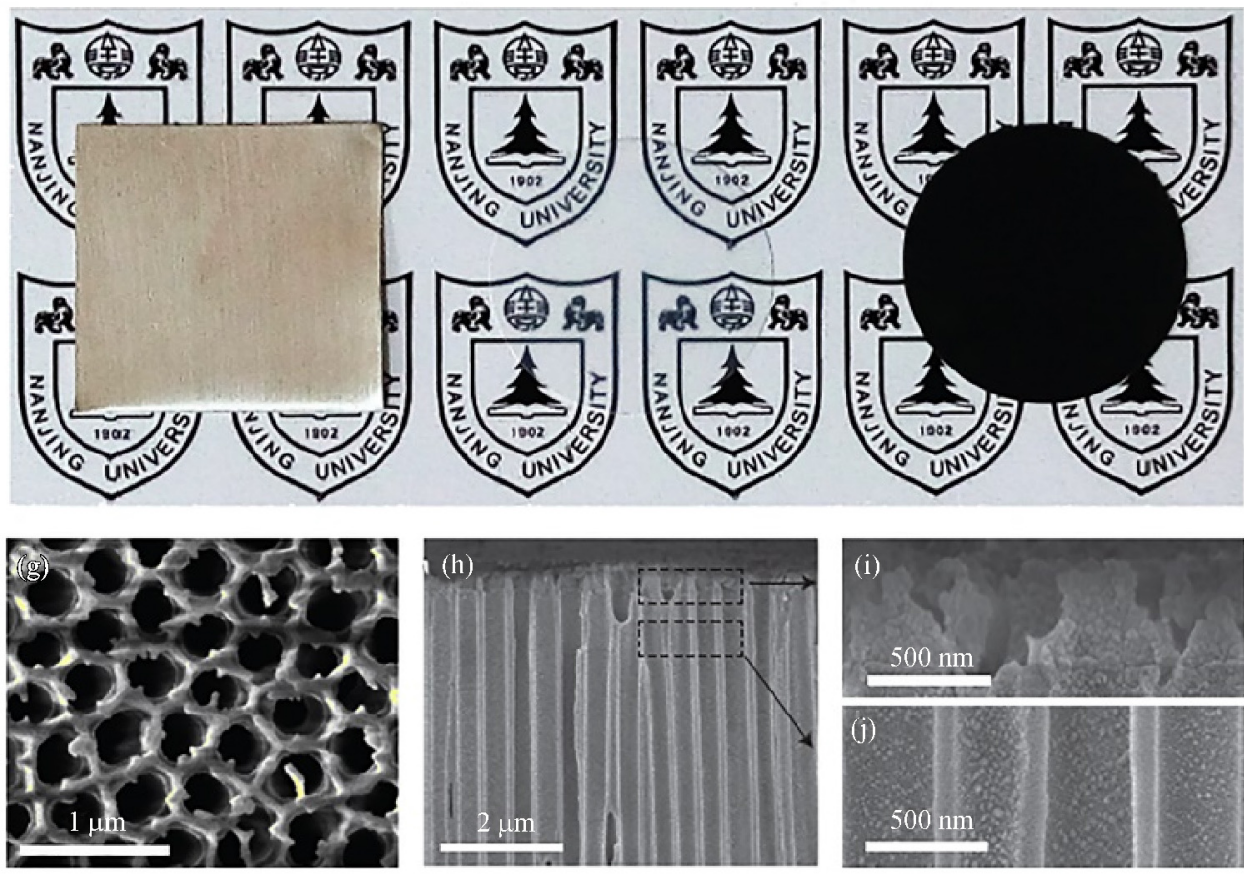

Fig. 2 Fabrication process and characterization of the Al NP-based plasmonic structure. (a) Aluminium foils served as the source materials for the entire fabrication process; (b) AAM fabricated by anodic oxidation; (c) The Al NP/AAM structure formed after the NP deposition; (d-f) Optical photographs of the aluminium foil (d), AAM sample (e) and Al NP/AAM structure (f) observed from the AAM side; (g,h) High-resolution SEM images of the structure: The top view (g) and cross-section (h); (i,j) Magnified images of the areas indicated in (h). Reprinted with permission from ref. [36]. Copyright 2016, Springer Nature.

well-known photothermal materials because of their broad light absorption, high stability, lightweight and low-cost. Nano carbon materials have many advantages, no toxic metals, stable performance, and can be easily made into all kinds of structures with different scale porous structures desirable for solar thermal applications.

In 2014, Ghasemi et al. reported a development of a new approach and corresponding material structure (doublelayer structure) that localizes the solar energy where evaporation occurs and minimizes the heat losses leading to enhanced solar thermal efficiency at low optical intensity in the open air while generating steam, as presented in Fig. 3. Ninety-seven percent of the irradiated solar power can be absorbed within the top exfoliated graphite layer. The bottom carbon foam which can limit the water flow rate to enhance the temperature of the generated vapour phase. The structure achieved solar thermal efficiency up to $85 \%$ at only $10 \mathrm{~kW} \cdot \mathrm{m}^{-2}$ [42].
In 2014, Selvakumar et al. demonstrated the transition of CNT-based tandem absorber (Ti/AlTiO/CoO/CNTs) from a near-perfect blackbody absorber to a solar selective absorber by varying the thicknesses of the CNTs and by suitably designing the bottom tandem absorber [44]. In 2016, Wang et al. investigated carbon-nanotube nanofluids for direct vapor generation [45]. A high evaporation efficiency (46.8\%) was obtained under a solar illumination power of $10 \mathrm{~kW} \cdot \mathrm{m}^{-2}$. In 2016, a bilayered material, consisting of a top self-floating hydrophobic CNT membrane and a bottom hydrophilic macroporous silica substrate, which had a solar thermal conversion efficiency of $82 \%$ was reported [46]. In 2017, Yin et al. fabricated a unique structure of a VACNT array with the optical absorptivity about $0.98-0.99$ over an ultra-broad spectral range of $200 \mathrm{~nm}-200 \mu \mathrm{m}$, as shown in Fig. 3. The evaporation rate of water assisted by VACNT arrays is 10 times that of bare water, the solar thermal conversion 

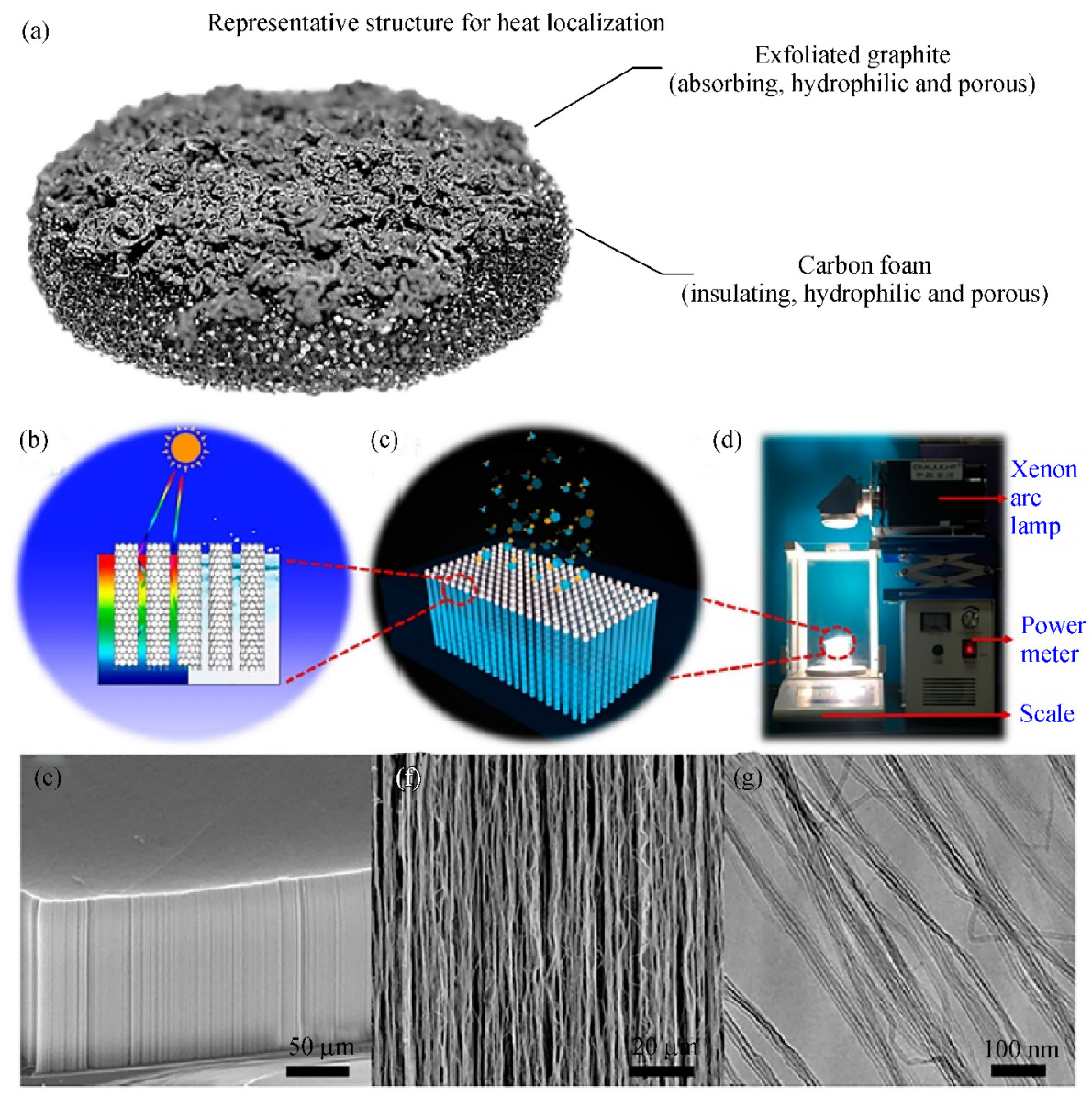

Fig. 3 (a) A picture of enhanced steam generation by the double-layer structure under the solar illumination of $10 \mathrm{~kW} \cdot \mathrm{m}^{-2}($ reprinted with permission from ref. [42]. Copyright 2014, Springer Nature); (b-d) Schematic illustration showing the experimental setup for solar steam generation using a vertically aligned carbon nanotube (VACNT) array floating on the water to absorb solar energy and to localize the heat; (e) A tilted view SEM image of the VACNT array; (f) A magnified side-view SEM image of the VACNT array; (g) A transmission electron microscopy image of CNT bundles. Reprinted with permission from Ref. [43]. Copyright 2017, American Chemical Society.

efficiency reached $90 \%$. This vertically aligned structure provided ultrafast water transport due to the frictionless wall of CNTs [43].

In 2015, Ito et al. developed a versatile porous graphene as a superior heat localization material for highly effective steam generation. The graphene particularly with nitrogen doping, has effective light absorption, low specific heat, low thermal conductivity, and mesoscopic porosity, which meet all the requirements for effective steam generation by heat localization energy efficiency of $80 \%$. They tailored pore size of the graphene by CVD temperatures. The generation of bubbles at the interface between hydrophobic graphene and water, enhanced thermal insulation of the system [47]. In 2017, Zhang et al. prepared a long-range vertically aligned graphene sheets membrane (VAGSM) via the antifreeze-assisted freezing technique. With the run-through channels facilitating the water transport, high light absorption capacity, the VAGSM achieved average water evaporation rates of 1.62 and $6.25 \mathrm{~kg} \cdot \mathrm{m}^{-2} \cdot \mathrm{h}^{-1}$ under
1 and 4 suns illumination with solar thermal conversion efficiency of up to $86.5 \%$ and $94.2 \%$, respectively [48]. Yang et al. demonstrated that functionalizing graphene using hydrophilic groups can greatly enhance the solar thermal steam generation efficiency. The surface effect attributed to the more hydrophilic feature of functionalized graphene influenced the water meniscus profile at the vapor-liquid interface, which led to thinner water films close to the three-phase contact line, where the water surface temperature is higher since the resistance of thinner water film is smaller, leading to more efficient evaporation [49].

Graphene composite with other nano materials also has been studied. In 2016, Zhang et al. reported a threedimensional (3D) graphene foam and phase change material (paraffin wax) composite which can enhance the heat storage capacity of the composite and release heat in an elongated period of time for sustained utilization [50]. To minimize heat loss, $\mathrm{Li}$ et al. designed a confined 2D 
water path, a thin layer of cellulose wrapped over the surface of the thermal insulator, a polystyrene foam. They thought the high efficiency of solar desalination is independent of the water quantity and can be maintained without thermal insulation of the container. A foldable graphene oxide film, serves as efficient solar absorbers (>94\%), vapor channels, and thermal insulators [51]. To gain an ideal structure suitable for solar steam generation, Jiang et al. introduced a bilayered hybrid biofoam composed of RGO and bacterial nanocellulose which possess large specific surface area, open microporous structure, excellent mechanical properties, and facile and scalable synthesis [52].

In 2017, Liu et al. introduced a novel bilayer structure which was composed of wood and GO for solar vapor generation [53]. The microporous wood provided broad optical absorption and served as a thermal insulator which greatly improved water evaporation rate, as shown in Fig. 4. In 2017, Ren et al. developed a hierarchical graphene foam (h-G foam) with continuous porosity grown via plasma-enhanced chemical vapor deposition, showing dramatic enhancement of broadband and omnidirectional absorption of sunlight. Used as a heating material, the external solar-thermal energy conversion efficiency of the h-G foam impressively reaches up to $\sim 93.4 \%$ [54].

Wang et al. designed a solar-driven interfacial evaporation system by integrating a paper-based reduced graphene oxide composite membrane on top of a silicone-based porous insulation layer. Under one-sun illumination achieved steady-state and time-averaged evaporation efficiency of $89.7 \%$ and $80.6 \%$, respectively [55]. Shi et al. designed and fabricated a bi-layered photothermal membrane with a porous film of rGO and polystyrene (PS) foam, and the evaporation rate and the energy conversion efficiency as high as $1.31 \mathrm{~kg} \cdot \mathrm{m}^{-2} \cdot \mathrm{h}^{-1}$ and $83 \%$, respectively [56]. In this year, many researchers also made other composites based on graphene, such as rGO sheets and mixed cellulose esters (MCE) membrane connected by polyethylenimine [57], reduced graphene oxide and polytetrafluoroethylene composite membrane [58].

Besides the novel and expensive materials graphene and CNT, carbon black and porous carbon also behaved a good performance in solar steam generation through proper design. In 2015, Liu et al. showed a floatable superhydrophobic carbon black based superhydrophobic gauze which was fabricated through dip coating of the lightabsorbing CB nanoparticle and PDMS [59]. 2017, Liu et al. fabricated a structure with carbon black (powder), hydrophilic porous paper and expanded polystyrene foam. With the excellent thermal insulation between the surface liquid and the bulk volume of the water and the suppressed radiative and convective losses from the absorber surface to the adjacent heated vapor, a record thermal efficiency of $88 \%$ is obtained under 1 sun, corresponding to the evaporation rate of $1.28 \mathrm{~kg} \cdot \mathrm{m}^{-2} \cdot \mathrm{h}^{-1}[60]$.
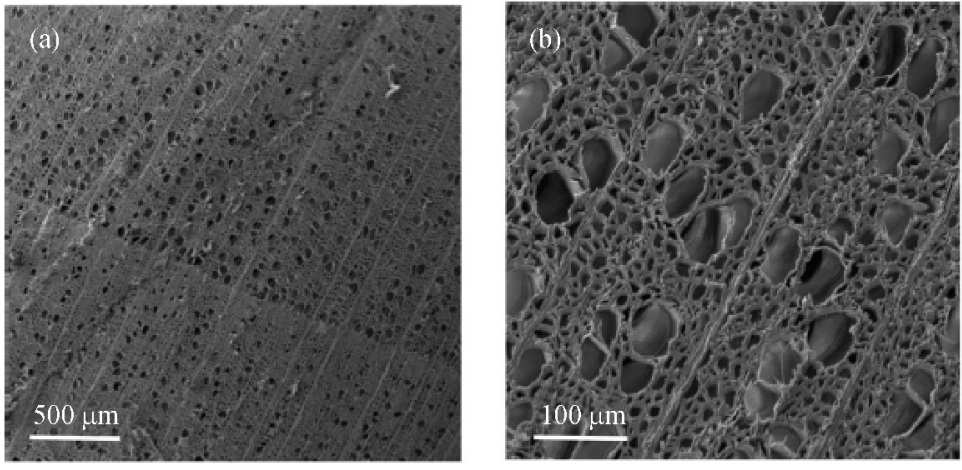

(d)

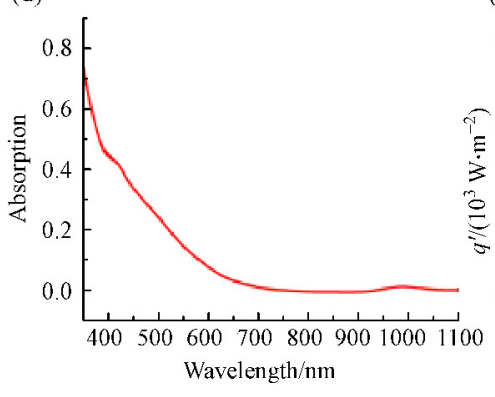

(e)

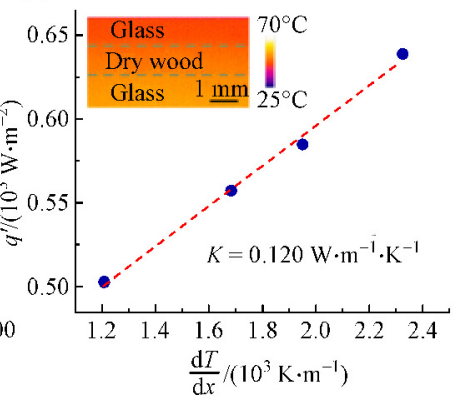

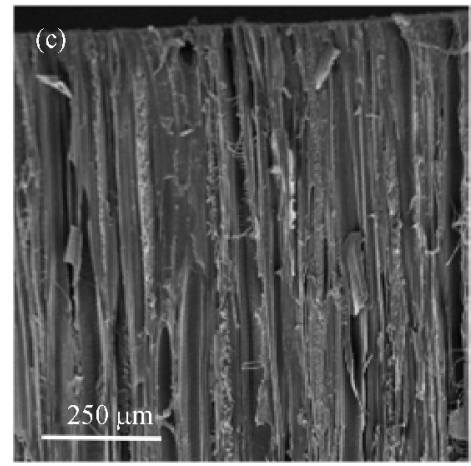

(f)

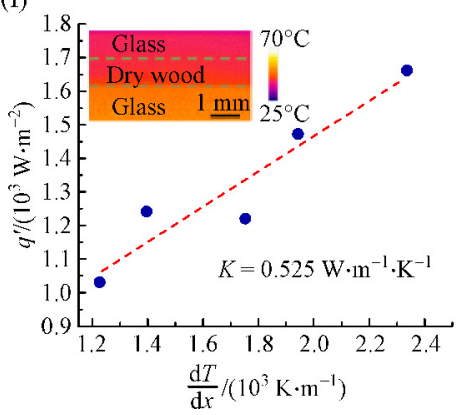

Fig. 4 (a, b) Low- and high-magnification SEM images of wood cross section showing the microchannel structures of wood; (c) SEM image showing the long microchannels in the wood; (d) Absorption spectrum of radially cut wood; (e,f) Thermal conductivity of wood in dry- and wet-states (inset of each panel showing the temperature gradient along the thickness of wood). Reprinted with permission from ref. [53]. Copyright 2017, American Chemical Society. 
2017, Xu et al. fabricated carbonized mushrooms for solar vapor generation which can achieve $\sim 78 \%$ conversion efficiencies under 1 sun illumination. The performance can be attributed to the unique natural structure of mushroom, which is suitable to reduce the heat loss [61]. Xue et al. reported a flame treatment natural wood as an ideal solar absorber, with ultra-high solar absorbance $(\sim 99 \%)$, low thermal conductivity $\left(0.33 \mathrm{~W} \cdot \mathrm{m}^{-1} \cdot \mathrm{K}^{-1}\right)$, good hydrophilicity, solar thermal efficiency of $\sim 72 \%$ under a solar intensity of $1 \mathrm{~kW} \cdot \mathrm{m}^{-2}$ [62].

In 2017, Wang et al. in situ converted cokes into carbons within the confined microporous zeolite structures which possessed ordered interconnected pores and tunable compositions. They studied the influences of porous structure and the oxygen content on energy conversion efficiencies [63]. Liu et al. presented work on a geopolymer-biomass mesoporous carbon composite (GBMCC) device with mesoporous and macroporous structures for solar water evaporation [64].

\subsection{Polymers}

Polymers provide flexibility and easy moldability but the choices of stable and water compatible photothermal polymers working within a broad solar spectrum are very limited. In 2015, Zhang et al. demonstrated a self-healing hydrophobic photothermal membrane which made by polypyrrole (PPy) coated on stainless steel (SS) mesh for interfacial solar heating [65]. The concept was embodied for the first time by a rational integration of surface hydrophobicity and light-to-heat conversion material onto mesh-based membranes exhibiting significantly enhanced water evaporation rates in comparison to conventional bulk heating scheme. Inspired by the natural transpiration process of plants, in 2017, Wu et al. developed a woodpolydopamine-based photothermal material for solarsteam generation. They used the wood and polydopamine derived from natural products and the solar-steam generation efficiency reaches $87 \%$ under 1.0 sun [66]. Huang et al. reported the fabrication of a polypyrrolecoated interfacial solar membrane using a versatile dipcoating method, which enables solar vapor generation efficiency of $72 \%$ for the purpose of desalination [67].

In 2018, Zhao et al. demonstrated a HNG based on PVA and PPy that serves as an independent solar vapour generator (Fig. 5) [68]. The floating HNG sample evaporated water with a record high rate of $3.2 \mathrm{~kg} \cdot \mathrm{m}^{-2} \cdot \mathrm{h}^{-1}$ via $94 \%$ solar energy from 1 sun irradiation. They thought the reduced latent heat of water evaporation in the molecular mesh under natural sunlight had a tremendous impact on. Chen et al. synthesized the polymer poly(1,3,5-hexahydro-1,3,5-triazine), which could be processed into a self-floating monolithic foam [69]. The single component foam can be used as an evaporator with an efficiency $80 \%$ even at 0.5 sun, and the foam was mechanically strong, thermally stable to $300^{\circ} \mathrm{C}$ and chemically resistant to many organic solvents.

\subsection{Semiconductors and metal oxides}

Metal oxides are usually used as photocatalytic and photothermal catalytic materials in hydrogen production $[70,71]$, solar-driven $\mathrm{CO}_{x}$ reduction to hydrocarbons $[72,73]$. Recently, metal oxides are used in the application of solar water evaporation. Liu et al. investigated the solar driven heating performance of a bifunctional membrane consisting of $\mathrm{TiO}_{2}$ NPs, $\mathrm{Au}$ NPs and AAO in 2016 [29]. In 2017, $\mathrm{Li}$ et al. reported MXene $\left(\mathrm{Ti}_{3} \mathrm{C}_{2}\right)$ as a full solar spectrum absorber and effective photothermal material for solar water evaporation, which produced a light-to-water evaporation efficiency of $84 \%$ under one sun irradiation [74]. Although these semiconducting materials did work for photothermal energy harvest, their relatively high cost and the finite solar absorption due to their high refractive index and bandgap of semiconductors, are the two main problems.

In 2016, Zhu et al. synthesized black titania with a unique nanocage structure simultaneously with light trapping effect to enhance light harvesting, well-crystallized interconnected nanograins to accelerate the heat transfer from titania to water and with opening mesopores $(4-10 \mathrm{~nm})$ to facilitate the permeation of water vapor [75]. In 2017, Wang et al. fabricated a $\mathrm{Ti}_{2} \mathrm{O}_{3}$ nanoparticle-based thin-film device and validated its high solar vapor generation efficiency and stability, indicating its potential use in seawater desalination and purification [76]. Ye et al. reported that $\mathrm{TiO}_{x}(x<2)$ nanoparticles with tunable colors from white to gray to blue-gray to black could be synthesized by magnesium reduction of white P25 $\mathrm{TiO}_{2}$ nanocrystals [77]. Ding et al. (2017) presented oxygendeficient molybdenum oxide quantum dots $\left(\mathrm{MoO}_{3-x} \mathrm{QDs}\right)$, which possessed matching-absorption-spectrum to solar light in both visible and near infrared regions [78].

\subsection{Composite materials}

In order to improve the performance of the solar vapor generation, especially energy conversion efficiency, various works also made to combine these materials together. In 2017, Hu et al. demonstrated a free-floating RGO-SACNT aerogels, with porous structures built up with RGO sheets together with CNT and SA, possessed excellent absorption of solar spectrum (92\% across 200-2500 nm), good hydrophilicity and porous networks for efficient water supply and vapor channels, and thermal insulating property for heat localization, and therefore can enable about $83 \%$ energy transfer efficiency under $1 \mathrm{~kW} \cdot \mathrm{m}^{-2}$ [79]. Sharma and Rabinal used graphene-silver nanoparticle composites for effective solar absorption are prepared by coupling surface plasmon and optical absorption of 

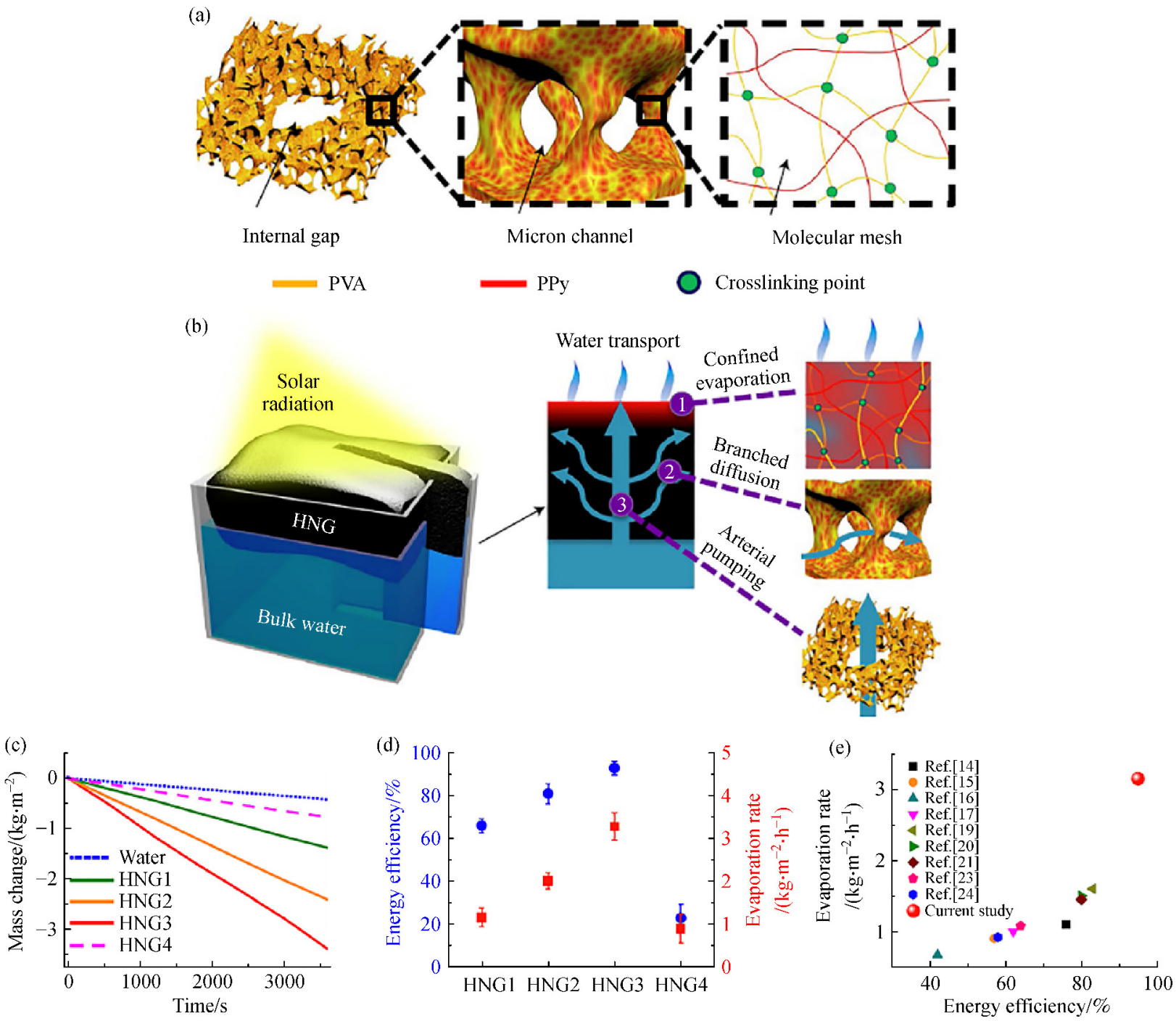

Fig. 5 (a) The hierarchically nanostructured gel (HNG) consists of hierarchical porous structures, including internal gaps, micron channels and molecular meshes, wherein the solar absorber (PPy) penetrates the polymeric polyvinyl alcohol (PVA) network of the gel; (b) Schematic of a typical solar vapour generation system and the water confinement strategy: (1) Under solar radiation, the solar absorbers in the molecular meshes of the floating generator are heated, facilitating the evaporation of water confined in the polymeric network (The water confined in the molecular mesh has a reduced evaporation enthalpy. The evaporated water can be rapidly recovered via (2) branched water diffusion and (3) pumping based on micron channels and internal gaps, respectively); (c) The mass loss of water and solar vapour generation energy efficiency; (d) The mass loss of water with corresponding evaporation rates of different $\mathrm{HNGs}$ under $1 \mathrm{sun}\left(1 \mathrm{~kW} \cdot \mathrm{m}^{-2}\right)$, with pure water as the control. Each error bar represents the deviation from at least 15 data points; (e) Comparison of HNG vapour generation performance and previous reports under 1 sun. Reprinted with permission from Ref. [68]. Copyright 2018, Springer Nature.

individual phases as low cost materials [80]. Fu et al. investigated the enhancing effects of $\mathrm{Au}$ nanoparticles on solar steam generation in graphene oxide nanofluids [81]. Yang et al. introduced an ultrathin 2D porous photothermal film based on $\mathrm{MoS}_{2}$ nanosheets and single-walled carbon nanotube films for solar vapor generation. The composite film exhibited an absorption of more than $82 \%$ over the whole solar spectrum range even with an ultrathin thickness of $\sim 120 \mathrm{~nm}$ and an evaporation efficiency of 91.5\% was achieved [82].
In 2018, Wang et al. reported a facile but effective approach to improve the photothermal performance by compositing the 2D rGO and 1D multiwalled carbon nanotubes, which have different nanomorphologies [83]. With rough surface, controllable nano-structure, loose internal porous structure and suitable wettability, the solar thermal conversion efficiency can reach up to $80.4 \%$ without extra accessory for thermal management. Yang et al. designed a bilayer film by assembling gold nanorod (AuNR) onto the interconnected single-walled carbon 
nanotube (SWNT) porous film, as shown in Fig. 6 [84]. The device got a nearly $94 \%$ water evaporation efficiency under $5 \mathrm{~kW} \cdot \mathrm{m}^{-2}$ solar irradiation.

\section{Thermal management}

\subsection{Nanofluids}

Many researches on nanofluids have shown that the suspensions of nanoparticles in conventional fluids can potentially enhance the efficiency of these solar thermal systems. The merit of this type of solar collector is that it can be designed to minimize the number of energy transfer steps, and convert solar illumination to thermal as much as possible instead of electricity

To investigate the inherent advantages of an optically tailored nanofluid system, in 2012, Taylor et al. have experimentally tested the feasibility of volumetrically absorbing, direct steam collection mediums [85]. Resulting temperature profiles and bubble dynamics are compared for the different samples. Lenert and Wang presented a combined modeling and experimental study to optimize the efficiency of liquid-based solar receivers seeded with carbon-coated absorbing nanoparticles [86]. In 2015, $\mathrm{Ni}$ et al. reported and measured vapor generation efficiencies of $69 \%$ at solar concentrations of 10 suns using graphitized carbon black, carbon black, and graphene nanoparticles suspended in water, representing a good performance in both transient and steady-state [87].

\subsection{Floating structures}

To realize the thermal management and reduce the heat loss, many works have been done on reducing the convective, conductive and radiative heat losses. Floating the reaction zone is one of the important method, and various of upholders were used to float the device, such as paper [88-90], AAO [34,36], polymer foam [51], and wood [91] etc. Under 1 sun illumination, the evaporation rate and efficiency of different nano materials with different carriers are listed in Table 1. In 2016, Ni et al. used a commercially cermet-coated copper substrate as the selective absorber, the insulation foam (polystyrene foam) to float the entire structure, a fabric wick to draw water through the foam, and a cap (bubble wrap) to prevent extraneous evaporation (Fig. 7) [92].

In 2017, Zhou et al. reported that spectrum-selective plasmonic absorbers with flexibly tuned bandwidth can be fabricated by a convenient self-assembly process [34]. The tunable plasmonic absorbers could float on water and had an extraordinary absorption (above 90\%) with absorption cutoff wavelengths flexibly tuned from visible $(\sim 550 \mathrm{~nm})$ to infrared $(\sim 2500 \mathrm{~nm})$. Zhu et al. designed plasmonic wood by uniformly decorating fine metal nanoparticles into the 3D mesoporous matrix of natural wood (plasmonic
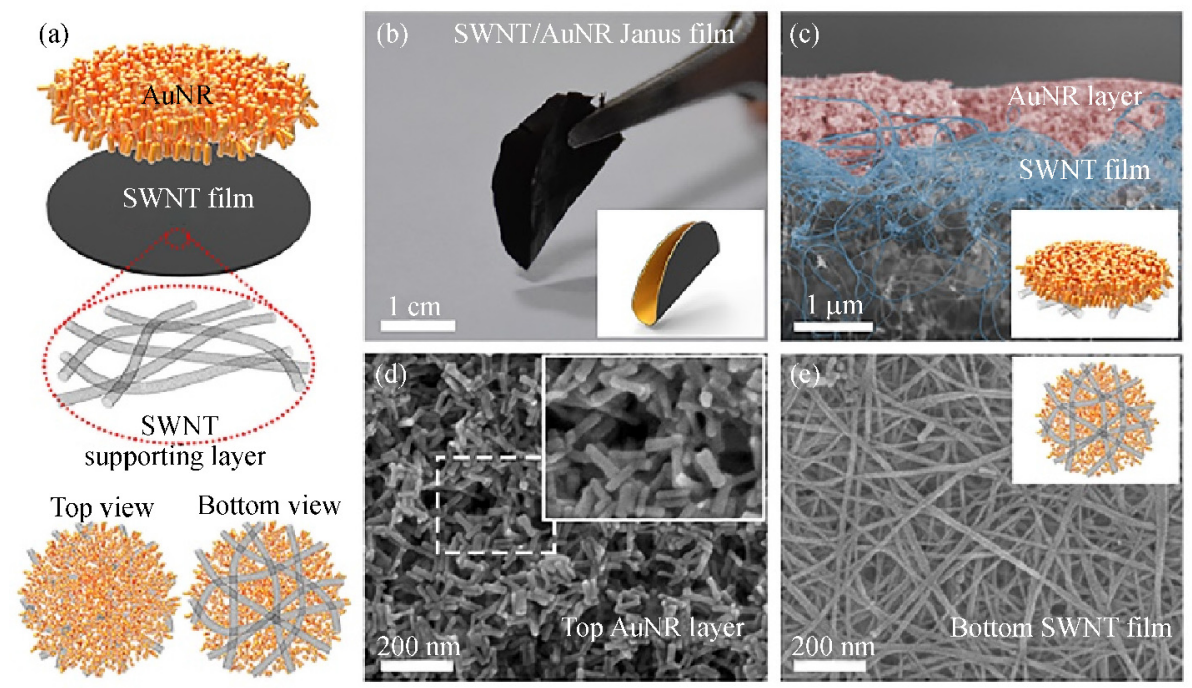

Fig. 6 Structure of the bilayer SWNT/AuNR film. (a) Schematic structure of the bilayer SWNT/AuNR Janus film viewed from different angles; (b) Photograph of the bilayer SWNT/AuNR Janus film in the cross-section direction (The inset of (b) is the structural model of the bilayer SWNT/AuNR film under bending conditions); (c) SEM image of the cross-section of the bilayer SWNT/AuNR Janus film (The inset of (c) is the structural model of the bilayer SWNT/AuNR Janus film); (d) SEM image of the top surface of the bilayer SWNT/AuNR film (The inset of (d) is the magnified SEM image of the AuNR layer); (e) SEM image of the bottom surface of the bilayer SWNT/AuNR film (The inset of (e) is the structural model of the bottom surface of the SWNT/AuNR film). Reprinted with permission from Ref. [84]. Copyright 2018, American Chemical Society. 
(a) Solar flux $1000 \mathrm{~W} \cdot \mathrm{m}^{-2}$

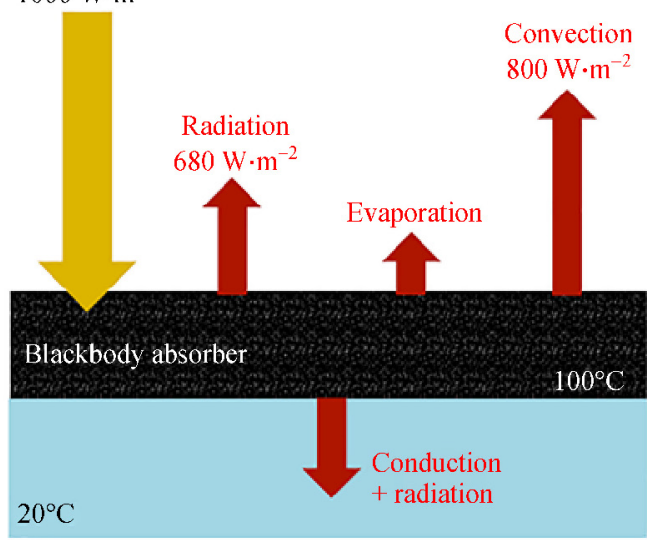

(b)

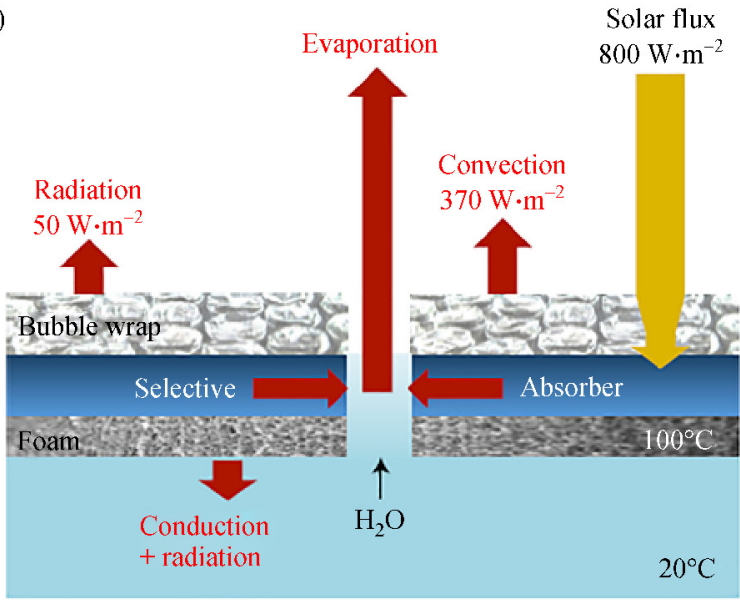

(c)

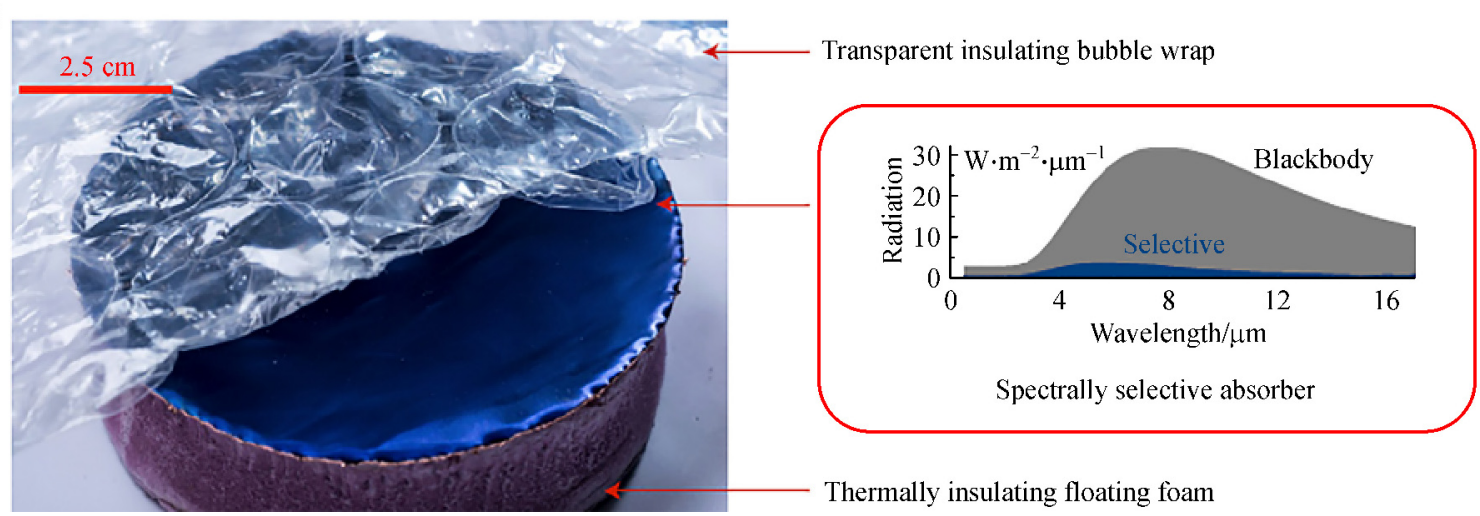

Fig. 7 (a) Energy balance and heat transfer diagram for a blackbody solar receiver operating at $100^{\circ} \mathrm{C}\left(\mathrm{The} 1000 \mathrm{~W} \cdot \mathrm{m}^{-2} \mathrm{delivered}\right.$ by the ambient solar flux is not enough to sustain the heat losses, and a $100^{\circ} \mathrm{C}$ equilibrium temperature cannot be reached); (b) Energy balance and heat transfer in the developed one-sun, ambient steam generator (OAS); (c) A photograph of the OAS composed of a commercial spectrally selective coating on copper to suppress radiative losses and to thermally concentrate heat to the evaporation region (The bubble wrap cover transmits sunlight, and minimizes convective losses. Slots are cut in the bubble wrap to allow steam to escape. Thermal foam insulates the hot selective absorber from the cool underlying water, and floats the entire structure. The inset compares thermal radiative losses at $100^{\circ} \mathrm{C}$ from a blackbody and the spectrally selective absorber). Reprinted with permission from Ref. [92]. Copyright 2016, Springer Nature.

wood) for high-efficiency solar steam generation, and exhibited high light absorption ability $(\sim 99 \%)$ over a broad wavelength range from 200 to $2500 \mathrm{~nm}$ [93].

\subsection{Structure designs}

In 2014, Ghasemi et al. fabricated a double-layer structure consisting of carbon foam (300-600 $\mu \mathrm{m})$ and exfoliated graphite [42]. The top exfoliated graphite was hydrophilic suitable for vapor escaption while the bottom carbon foam was insulating and limited porous structure which can support and float the whole device and also control the water quantity transferred to the top. In 2016, Li et al. fabricated a floating device consisting of a $2 \mathrm{D}$ water path by a thin layer of cellulose wrapped over the surface of the thermal insulator, a polystyrene foam, and a foldable graphene oxide film as the absorber [51]. Enabled by a confined 2D water path, this device can reach at an efficient of $80 \%$ under 1 sun illumination. In 2018, Li et al. reported a special structure with 1D water path (a coton rod) for water supply way and a hollow cone absorber (GO film), and with this structure, over $85 \%$ solar steam efficiency under one sun can be achieved without external optical or thermal management [94]. In 2018, Wang et al. used a 3D photothermal cone to improved light-harvesting and thermal management for efficient solar-drive water evaporation [95]. Ni et al. presented an experimental demonstration of a salt-rejecting evaporation structure that can operated continuously under sunlight to generate clean vapor while floating in a saline body of water [96].

In 2018, Zhuang et al. reported a concept of interfacial solar vapor generation based on tunable plant transpiration [97]. The transpiration efficiency can be enhanced or suppressed through engineering the solar absorber-leaf interface by sensing the surface temperature and relative humidity in the surrounding environment. Morciano et al. demonstrated an efficient steam generation device with a combination of efficient solar absorption, capillary water 
feeding and narrow gap evaporation process, which can also be achieved through common materials (Fig. 8) [98]. In 2018, Xue et al. designed a compact solar-thermal membrane distillation system with three structure features: highly localized solar-thermal heating, effective cooling strategy, and recycling the latent heat, as presented in Fig. 8 [99].

\subsection{Mass transfer}

Mass transfer including water transport and vapor escape is another key factor for improving the efficiency of water vapor generation, which is also closely related to the thermal management. Optimizing the proper amount of water supply is very important. Hydrophilic $[46,49,100]$ or

(a)

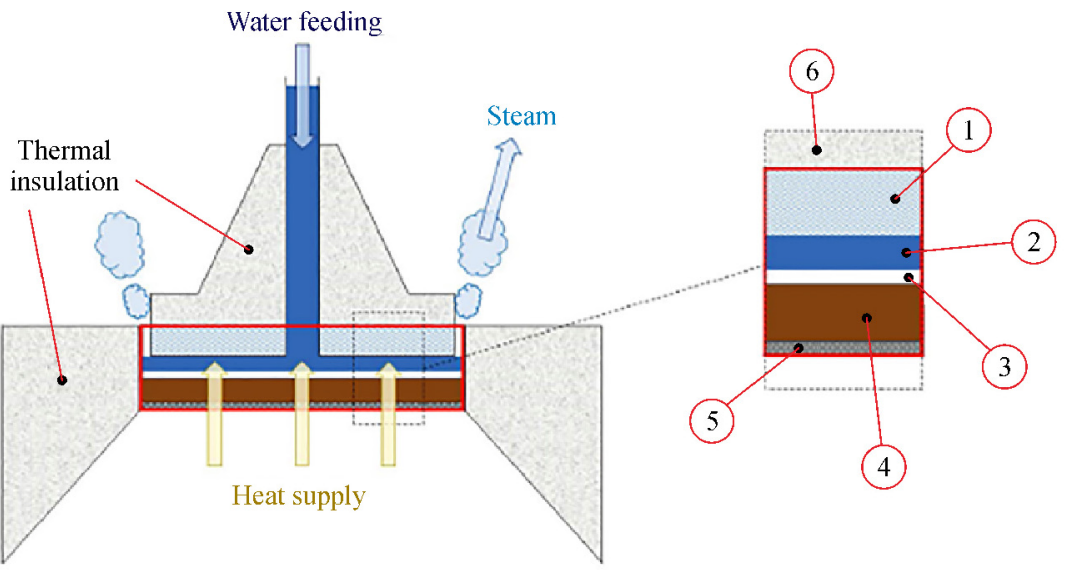

(b)

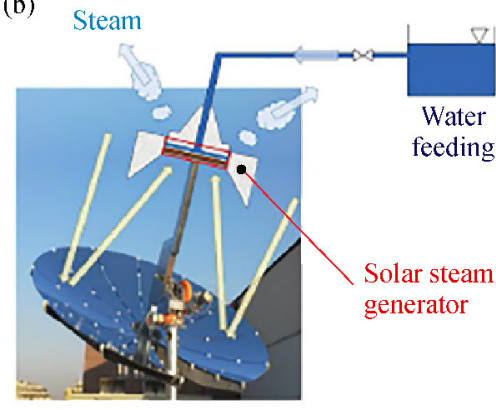

Solar concentrator

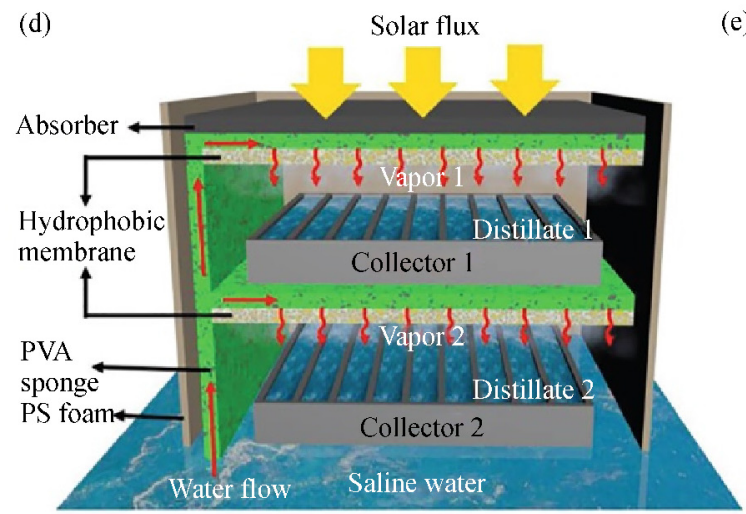

(c)

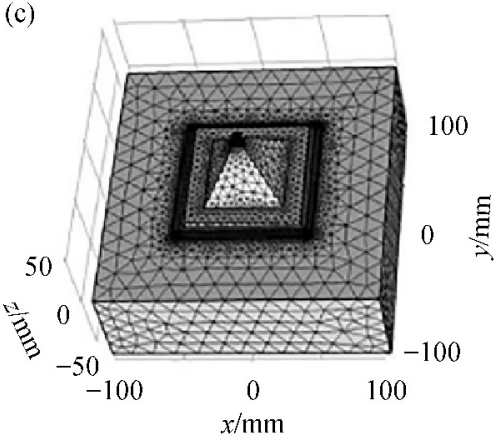

(e)

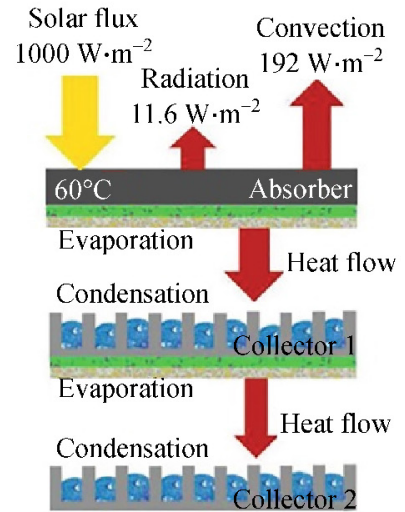

Fig. 8 (a) Schematics and section of the solar steam generator: (1) Glass; (2) Narrow gap of evaporating water; (3) Hydrophilic cotton; (4) Copper plate; (5) Commercial solar absorption material (e.g., $\mathrm{TiNO}_{x}$ ); (6) Polystyrene; (b) Coupling between the steam generator and a solar concentrator; (c) Computational setup (Reprinted with permission from ref. [98]); (e) The cross-sectional view to exhibit every component of the system and the water transfer process; (f) Energy balance and heat transfer diagram for an absorber (assuming reaching $60^{\circ} \mathrm{C}$ ) with thermal emittance of $5 \%$ under the solar flux of $1000 \mathrm{~W} \cdot \mathrm{m}^{-2}$. Reprinted with permission from Ref. [99]. 
hydrophobic [59,65,101], pore size and coupling with other physics-assisted enhancement etc. have great impacts on the water transport and the efficiency of water vapor generation.

In the absence of water transport studies, direct evaporation usually requires hydrophobicity. In 2014, Zeng et al. fabricated floatable low-density millimetersized hollow carbon beads which were hydrophobic and achieved an evaporation rate of $1.28 \mathrm{~L} \cdot \mathrm{m}^{-2} \cdot \mathrm{h}^{-1}[102]$. While considering heat management in most designs, attention was paid to water transport control which needs hydrophilicity feature. In 2017, Yang et al. demonstrated that functionalizing graphene using hydrophilic groups can greatly enhance the solar thermal steam generation efficiency [49]. They explained the hydrophilic feature would influence the water meniscus profile at the vaporliquid interface due to capillary effect, which will lead to thinner water films close to the three-phase contact line, leading to more efficient evaporation.

In 2015, Ito et al. synthesized a versatile porous hydrophobic graphene with nitrogen doping as a superior heat localization material for highly effective steam generation [47]. The pore sizes of the graphene can be tailored by CVD temperatures from 100-300 nm to $1-2 \mu \mathrm{m}$. The evaporation rate of $1.50 \mathrm{~kg} \cdot \mathrm{m}^{-2} \cdot \mathrm{h}^{-1}$ for $\mathrm{N} 950$ (pore size 1-2 $\mu \mathrm{m}$ ) which was better than the samples with small pore size and without nitrogen doping can be achieved. In 2017, Zhang et al. prepared long-range VAGSM with lateral dimensions of $30-50 \mu \mathrm{m}$ as the highly efficient solar thermal converter for generation of clean water (Fig. 9) [48]. The run-through channels facilitating the water transport of the VA-GSM, and achieved average water evaporation rates of 1.62 and $6.25 \mathrm{~kg} \cdot \mathrm{m}^{-2} \cdot \mathrm{h}^{-1}$ under 1 and 4 suns illumination, respectively.

In 2018, Liu et al. presented a GBMCC device with mesoporous and macroporous structures for harvesting solar energy [64]. They reported the first photothermal material using robust bulk mesoporous carbons, and the first photothermal devices by combining solar energy with other physics fields, using wind-driven negative pressure to generate water vapor with very high efficiency. The device gave water evaporation rates of 1.58 and $2.71 \mathrm{~kg} \cdot \mathrm{m}^{-2} \cdot \mathrm{h}^{-1}$ under 1 and 3 suns illumination, respectively, and also achieved a record high water vapor generation rate of $7.55 \mathrm{~kg} \cdot \mathrm{m}^{-2} \cdot \mathrm{h}^{-1}$ under 1 sun solar intensity at the wind speed of $3 \mathrm{~m} \cdot \mathrm{s}^{-1}$ (Fig. 10, Table 1). Cui et al. reported a rational combination of photo-electrothermal effect on an all-graphene hybrid architecture, and the unique graphene evaporator reached a high water (a)

Ethanol GO suspension

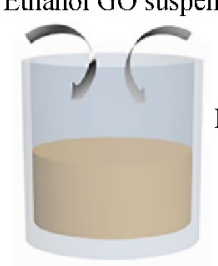

(b)

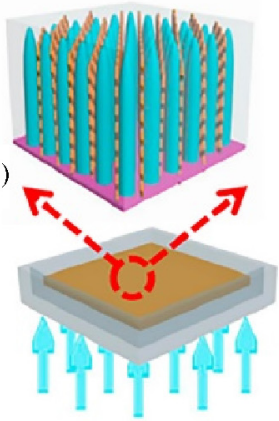

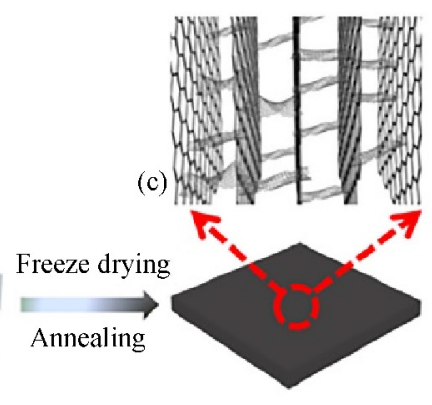
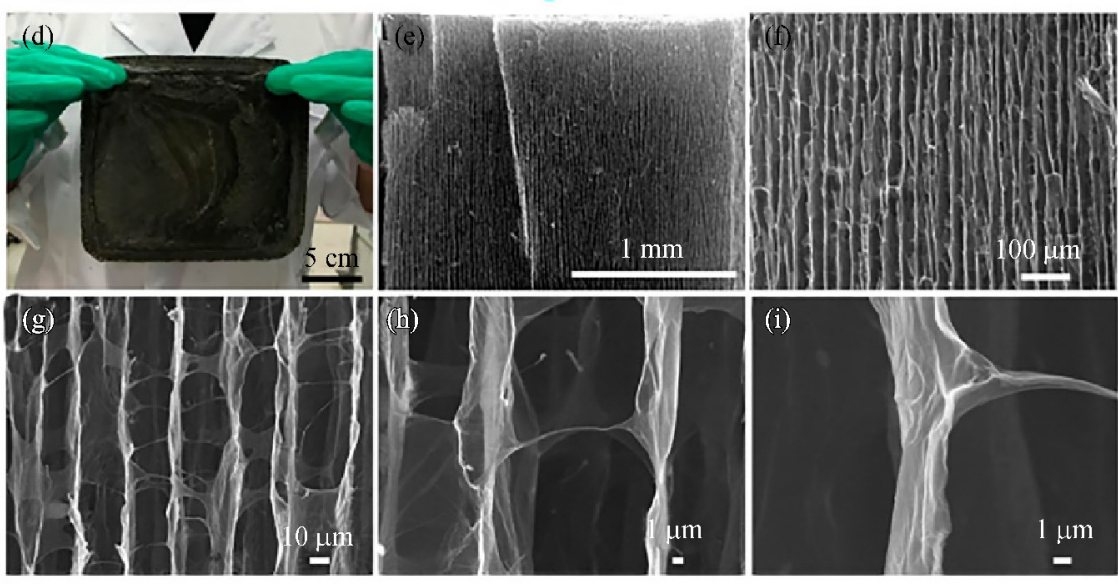

Fig. 9 (a) GO suspension with a small amount of ethanol; (b) Directional freeze casting of GO mixture in a PTFE mold, which is placed on the surface of liquid nitrogen to induce the freezing direction from the bottom to top; (c) VA-GSM is obtained after freeze-drying and thermal annealing; (d) Photograph of monolith VA-GSM with a size of $16 \mathrm{~cm} \times 16 \mathrm{~cm}$; (e-i) SEM images of VA-GSM with different magnifications. Reprinted with permission from Ref. [48]. Copyright 2017, American Chemical Society. 


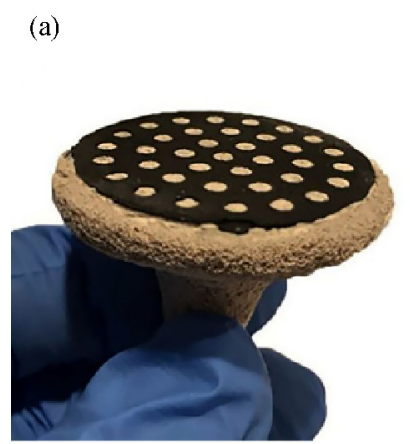

(b) $\Delta$

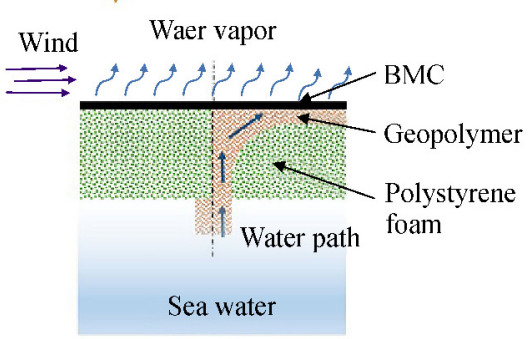

(c)

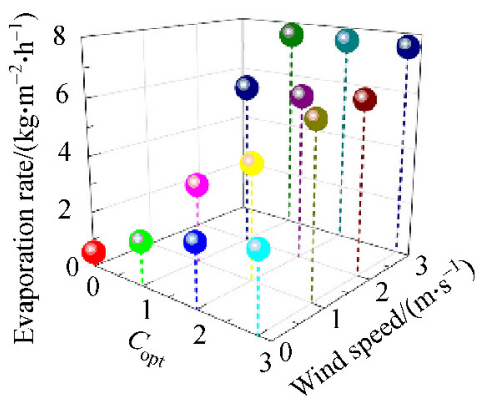

Fig. 10 (a) A photo of a typical GBMCC device composing with geopolymer (brown) and biomass mesoporous carbon (BMC, black); (b) Schematic of the mass and heat transportation showing water was transferred from the bottom through the macroporous geopolymer and then to the BMC layer heated by the solar energy (The effect can be enhanced by the negative pressure caused by wind); (c) The influence of sunlight intensity and wind speed on evaporation rate. Reprinted with permission from Ref. [64]. Copyright 2018, John Wiley and Sons.

Table 1 Solar steam generation performances of different materials ${ }^{\text {a) }}$

\begin{tabular}{|c|c|c|c|c|c|}
\hline Samples & Carriers & Solar absorption $1 \%$ & $\begin{array}{c}\text { Energy conversion effi- } \\
\text { ciency } 1 \%\end{array}$ & $\begin{array}{l}\text { Evaporation rates } \\
/\left(\mathrm{kg} \cdot \mathrm{m}^{-2} \cdot \mathrm{h}^{-1}\right)\end{array}$ & Ref. \\
\hline $\mathrm{CNT} /$ macroporous silica & Silica & - & 82 & 1.31 & [34] \\
\hline $\mathrm{Ag} /$ diatomite & Paper & - & 92.2 & 1.39 & [38] \\
\hline CNT Arrays & - & 99 & 30 & - & [43] \\
\hline CNT nanofluids & - & - & - & 1.1 & {$[45]$} \\
\hline Porous $N$-doped graphene & - & - & 80 & 1.5 & [47] \\
\hline Functionalized-rGO & - & - & 48 & 0.47 & [49] \\
\hline Hierarchical graphene foam & - & $85-95$ & 91.4 & 1.4 & {$[54]$} \\
\hline $\mathrm{rGO} / \mathrm{MCE}$ & $\begin{array}{l}\text { Cellulose mem- } \\
\text { brane }\end{array}$ & - & 60 & 0.838 & {$[57]$} \\
\hline Carbonized Mushroom & - & - & 78 & 1.475 & {$[61]$} \\
\hline Flamed-treated wood & Wood & - & 72 & 1.05 & {$[62]$} \\
\hline $\begin{array}{l}\text { Mesoporous bulk carbons driven } \\
\text { from biomass }\end{array}$ & Geololymer & $90-95$ & - & $\begin{array}{c}1.58,2.85,5.90 \text { and } 7.55, \\
\text { with } 0,1,2 \text { and } 3 \mathrm{~m} \cdot \mathrm{s}^{-1} \text { wind }\end{array}$ & [64] \\
\hline HNG & - & $>95$ & 94 & 3.2 & {$[68]$} \\
\hline MXene $\mathrm{Ti}_{3} \mathrm{C}_{2}$ & PVDF Membrane & - & 84 & 1.33 & [74] \\
\hline $\mathrm{Ti}_{2} \mathrm{O}_{3}$ Nanoparticles & $\begin{array}{l}\text { Cellulose mem- } \\
\text { brane }\end{array}$ & 92.5 & $92.1 \pm 3.2$ & 1.32 & [76] \\
\hline GO-based aerogels & - & 92 & 86.5 & 1.622 & [79] \\
\hline Carbon beads & - & - & - & 1.28 & [84] \\
\hline Photo-electro-thermal Graphene & - & - & - & $2.01-2.61$ & {$[85]$} \\
\hline CNT modified filter paper & Paper & - & 75 & 1.15 & {$[90]$} \\
\hline Carbon sponge & - & $>95$ & 85 & 1.31 & {$[104]$} \\
\hline
\end{tabular}

a) The solar absorption, the energy conversion efficiency and the evaporation rates of various photothermal materials under 1 sun.

production rate of $2.01-2.61 \mathrm{~kg} \cdot \mathrm{m}^{-2} \cdot \mathrm{h}^{-1}$ under solar illumination of $1 \mathrm{~kW} \cdot \mathrm{m}^{-2}[103]$.

Table 1 summarizes the materials and performances of the recent photothermal devices, the materials' optical properties for solar absorption, the devices' parameters including energy conversion efficiency, evaporation rates under 1 sun are compared. Generally, a black solar absorber composites with a hydrophilic carrier, which can help the evaporation achieving water supply balance. High absorbance is not a sufficient condition for achieving efficient water evaporation, such as CNT arrays, which has an absorbance of $99 \%$ but the evaporation efficiency only $30 \%$. HNG with molecular mesh structure achieved water molecule cluster evaporation, which can reduce the latent 
heat of evaporation of water, and a high evaporation rate of $3.2 \mathrm{~kg} \cdot \mathrm{m}^{-2} \cdot \mathrm{h}^{-1}$ was achieved. Graphene utilized solar thermal and solar photovoltaic together to improve the water evaporation rate to $2.01-2.61 \mathrm{~kg} \cdot \mathrm{m}^{-2} \cdot \mathrm{h}^{-1}$. The highest evaporation rate $\left(7.55 \mathrm{~kg} \cdot \mathrm{m}^{-2} \cdot \mathrm{h}^{-1}\right)$ was obtained by using geopolymer as a carrier, mesoporous carbon as a photothermal conversion layer, and a weak wind was used to form an evaporation negative pressure, which was about 15 fold of the of the natural evaporation rate of water $\left(0.502 \mathrm{~kg} \cdot \mathrm{m}^{-2} \cdot \mathrm{h}^{-1}\right)$. New approaches including developing better materials, optimized thermal management or using concentrated solar apparatuses are promising to further enhance the evaporation rates.

The evaporation rate and the energy conversion efficiency are two key technical indicators in the field of solar vapor generation. The evaporation rate is generally defined as the mass of water evaporated per unit area per unit area under the corresponding solar energy. The energy conversion efficiency $\left(\eta_{\text {th }}\right)$ is used to evaluate the solar-tovapor efficiency. It is defined as below:

$$
\eta_{\mathrm{th}}=\frac{\dot{m} h_{\mathrm{LV}}}{C_{\mathrm{opt}} q_{i}}
$$

where $\dot{m}$ is the mass loss rate per unit area, $h_{\mathrm{LV}}$ is the total enthalpy of sensible heat (from initial water temperature to evaporation temperature, specific heat of water 4.2 $\left.\mathrm{J} \cdot \mathrm{g}^{-1} \cdot \mathrm{K}^{-1}\right)$ and latent heat of phase change $\left(2256 \mathrm{~J} \cdot \mathrm{g}^{-1}\right)$, $C_{\text {opt }}$ is the optical concentration, and $q_{i}$ is the nominal direct solar irradiation of $1 \mathrm{~kW} \cdot \mathrm{m}^{-2}$. Usually, the background data in dark environment will be subtracted when calculating the evaporation rate.

\section{Challenges and future perspectives}

In spite of the amazing achievements have been made in the novel materials and structures, most of the reported results are still in the early stage and laboratory a scale, more effort and innovations are still needed towards practical applications in which low cost, large area, mechanical robust, environmentally friendly have to be considered and met. System integrations and development are also very important before the field tests. For practical applications, there are still many obstacles to overcome. The following are some of the major challenges.

\subsection{Challenges}

(i) The problem of crystallization and precipitation of salts $\left(\mathrm{NaCl}, \mathrm{CaSO}_{4}, \mathrm{MgSO}_{4}\right.$, etc. in sea water) is the primary one, which is always present during the evaporation process. The crystallization and precipitation of salts can occur on the materials' surface, such as the interlayer of graphene, the inwall of the carbon nanotube, the surface of the metal nanoparticles and the pores of the porous carbon, which will seriously hinder the water transfer, heat transfer and the water steam formation.

(ii) For some of these materials, such as gold, silver, semiconductors, metal nanoparticles, graphene and carbon nanotubes are relatively expensive and have a certain negative impact on the environment. In addition, the stability and scalability of these devices which are still in the laboratory scale and early stage, facing relatively more difficulties and challenges in the actual application environment.

(iii) Although recent studies have explored on improving the device structures, structural designs are still one of the main issues. How to achieve the balance between water transmission and steam formation, how to achieve heat management and how to achieve corresponding adjustments with environmental changing are still requiring innovative structural designs.

\subsection{Perspectives}

Solar-driven water evaporation can make full use of low quality solar energy, be friendly to environment and easy to manufacture, which make it attractive and economical to effectively solve the global problems of energy and clean water scarcity. Solar evaporation assisted by the photothermal materials towards brine water treatment for the purpose of zero-liquid discharge and/or salt extraction is expected to grow with the demand and regulation of the global environment [105].

Materials which can be thermal stable, robust, flexible, easy recycle, etc. are eager to be developed in practical applications. The design of the device, coupled with other energy enhancement, the collection of pure water, effectively utilizes the latent heat generated by water condensation are also important in solar evaporation and distillation applications. With the optimized structural designs, energy management, fully combine with other renewable energy sources to realize large-scale integrated devices on a unlimited area, and make seawater desalination no longer high cost, high energy consumption, the solar-driven water evaporation is expected to realize in the near future.

Acknowledgements This work is supported by the Science and Technology Commission of Shanghai Municipality (STCSM) (Grant No. 17230732700), the Innovate UK (Grant No. 104013), the institutional strategic grant-Global Challenges Research Fund (GCRF), that City, University of London, receives from Research England, UK Research and Innovation (UKRI).

Open Access This article is licensed under a Creative Commons Attribution 4.0 International License, which permits use, sharing, adaptation, distribution and reproduction in any medium or format, as long as you give appropriate credit to the original author(s) and the source, provide a link to the Creative Commons licence, and indicate if changes were made. The images or other third party material in this article are included in the article's Creative Commons licence, unless indicated otherwise in a credit line to the material. If material is not included in the article's Creative Commons licence and your 
intended use is not permitted by statutory regulation or exceeds the permitted use, you will need to obtain permission directly from the copyright holder. To view a copy of this licence, visit http://creativecommons.org/licenses/by/4.0/.

\section{References}

1. Shannon M A, Bohn P W, Elimelech M, Georgiadis J G, Marinas B J, Mayes A M. Science and technology for water purification in the coming decades. Nature, 2008, 452(7185): 301-310

2. Burheim O S, Seland F, Pharoah J G, Kjelstrup S. Improved electrode systems for reverse electro-dialysis and electro-dialysis. Desalination, 2012, 285: 147-152

3. Mei Y, Tang C Y Y. Recent developments and future perspectives of reverse electrodialysis technology: A review. Desalination, 2018, 425: 156-174

4. Huyskens C, Helsen J, de Haan A B. Capacitive deionization for water treatment: Screening of key performance parameters and comparison of performance for different ions. Desalination, 2013, 328: $8-16$

5. Greenlee L F, Lawler D F, Freeman B D, Marrot B, Moulin P. Reverse osmosis desalination: Water sources, technology, and today's challenges. Water Research, 2009, 43(9): 2317-2348

6. Sobana S, Panda R C. Review on modelling and control of desalination system using reverse osmosis. Reviews in Environmental Science and Biotechnology, 2011, 10(2): 139-150

7. Alkhudhiri A, Darwish N, Hilal N. Membrane distillation: A comprehensive review. Desalination, 2012, 287: 2-18

8. García-Rodríguez L, Gomez-Camacho C. Conditions for economical benefits of the use of solar energy in multi-stage flash distillation. Desalination, 1999, 125(1-3): 133-138

9. Zhao D F, Xue J L, Li S, Sun H, Zhang Q D. Theoretical analyses of thermal and economical aspects of multi-effect distillation desalination dealing with high-salinity wastewater. Desalination, 2011, 273(2-3): 292-298

10. Alarcón-Padilla D C, Garcia-Rodriguez L. Application of absorption heat pumps to multi-effect distillation: A case study of solar desalination. Desalination, 2007, 212(1-3): 294-302

11. Farid M, Al-Hajaj A W. Solar desalination with a humidificationdehumidification cycle. Desalination, 1996, 106(1-3): 427-429

12. Khawaji A D, Kutubkhanah I K, Wie J M. Advances in seawater desalination technologies. Desalination, 2008, 221(1-3): 47-69

13. Jin H, Lin G, Bai L, Zeiny A, Wen D. Steam generation in a nanoparticle-based solar receiver. Nano Energy, 2016, 28: 397406

14. Farokhnia N, Irajizad P, Sajadi S M, Ghasemi H. Rational micro/ nanostructuring for thin-film evaporation. Journal of Physical Chemistry C, 2016, 120(16): 8742-8750

15. Nagata Y, Usui K, Bonn M. Molecular mechanism of water evaporation. Physical Review Letters, 2015, 115(23): 236102

16. Gueymard C A. The sun's total and spectral irradiance for solar energy applications and solar radiation models. Solar Energy, 2004, 76(4): 423-453

17. Liu G, Xu J, Wang K. Solar water evaporation by black photothermal sheets. Nano Energy, 2017, 41: 269-284

18. Deng Z, Zhou J, Miao L, Liu C, Peng Y, Sun L, Tanemura S. The emergence of solar thermal utilization: Solar-driven steam generation. Journal of Materials Chemistry. A, 2017, 5(17): 7691-7709

19. Meng X, Liu L, Ouyang S, Xu H, Wang D, Zhao N, Ye J. Nanometals for solar-to-chemical energy conversion: From semiconductor-based photocatalysis to plasmon-mediated photocatalysis and photo-thermocatalysis. Advanced Materials, 2016, 28(32): 6781-6803

20. Chen H, Shao L, Li Q, Wang J. Gold nanorods and their plasmonic properties. Chemical Society Reviews, 2013, 42(7): 2679-2724

21. Lukianova-Hleb E, Hu Y, Latterini L, Tarpani L, Lee S, Drezek R A, Hafner J H, Lapotko D O. Plasmonic nanobubbles as transient vapor nanobubbles generated around plasmonic nanoparticles. ACS Nano, 2010, 4(4): 2109-2123

22. Fang Z, Zhen Y R, Neumann O, Polman A, Garcia de Abajo F J, Nordlander P, Halas N J. Evolution of light-induced vapor generation at a liquid-immersed metallic nanoparticle. Nano Letters, 2013, 13(4): 1736-1742

23. Neumann O, Urban A S, Day J, Lal S, Nordlander P, Halas N J. Solar vapor generation enabled by nanoparticles. ACS Nano, 2013, 7(1): 42-49

24. Neumann O, Feronti C, Neumann A D, Dong A, Schell K, Lu B, Kim E, Quinn M, Thompson S, Grady N, et al. Compact solar autoclave based on steam generation using broadband lightharvesting nanoparticles. Proceedings of the National Academy of Sciences of the United States of America, 2013, 110(29): 1167711681

25. Hogan N J, Urban A S, Ayala-Orozco C, Pimpinelli A, Nordlander P, Halas N J. Nanoparticles heat through light localization. Nano Letters, 2014, 14(8): 4640-4645

26. Guo A, Fu Y, Wang G, Wang X. Diameter effect of gold nanoparticles on photothermal conversion for solar steam generation. RSC Advances, 2017, 7(8): 4815-4824

27. Wang Z, Liu Y, Tao P, Shen Q, Yi N, Zhang F, Liu Q, Song C, Zhang D, Shang W, et al. Bio-inspired evaporation through plasmonic film of nanoparticles at the air-water interface. Small, 2014, 10(16): 3234-3239

28. Liu Y, Yu S, Feng R, Bernard A, Liu Y, Zhang Y, Duan H, Shang $\mathrm{W}$, Tao P, Song C, et al. A bioinspired, reusable, paper-based system for high-performance large-scale evaporation. Advanced Materials, 2015, 27(17): 2768-2774

29. Liu Y, Lou J, Ni M, Song C, Wu J, Dasgupta N P, Tao P, Shang W, Deng T. Bioinspired bifunctional membrane for efficient clean water generation. ACS Applied Materials \& Interfaces, 2016, 8(1): 772-779

30. Yu S, Zhang Y, Duan H, Liu Y, Quan X, Tao P, Shang W, Wu J, Song C, Deng T. The impact of surface chemistry on the performance of localized solar-driven evaporation system. Scientific Reports, 2015, 5(1): 13600

31. Bae K, Kang G, Cho S K, Park W, Kim K, Padilla W J. Flexible thin-film black gold membranes with ultrabroadband plasmonic nanofocusing for efficient solar vapour generation. Nature Communications, 2015, 6(1): 10103

32. Tian L, Luan J, Liu K K, Jiang Q, Tadepalli S, Gupta M K, Naik R $\mathrm{R}$, Singamaneni S. Plasmonic biofoam: A versatile optically active material. Nano Letters, 2016, 16(1): 609-616

33. Zhou L, Tan Y, Ji D, Zhu B, Zhang P, Xu J, Gan Q, Yu Z, Zhu J. 
Self-assembly of highly efficient, broadband plasmonic absorbers for solar steam generation. Science Advances, 2016, 2(4): e1501227

34. Zhou L, Zhuang S, He C, Tan Y, Wang Z, Zhu J. Self-assembled spectrum selective plasmonic absorbers with tunable bandwidth for solar energy conversion. Nano Energy, 2017, 32: 195-200

35. Liu C, Huang J, Hsiung C E, Tian Y, Wang J, Han Y, Fratalocchi A. High-performance large-scale solar steam generation with nanolayers of reusable biomimetic nanoparticles. Advanced Sustainable Systems, 2017: 1600013

36. Zhou L, Tan Y, Wang J, Xu W, Yuan Y, Cai W, Zhu S, Zhu J. 3D self-assembly of aluminium nanoparticles for plasmon-enhanced solar desalination. Nature Photonics, 2016, 10(6): 393-398

37. Wang H, Miao L, Tanemura S. Morphology control of Ag polyhedron nanoparticles for cost-effective and fast solar steam generation. Solar RRL, 2017, 1(3-4): 1600023

38. Fang J, Liu Q, Zhang W, Gu J, Su Y, Su H, Guo C, Zhang D. Ag/ diatomite for highly efficient solar vapor generation under one-sun irradiation. Journal of Materials Chemistry. A, 2017, 5(34): 1781717821

39. Chen F, Gong A S, Zhu M, Chen G, Lacey S D, Jiang F, Li Y, Wang Y, Dai J, Yao Y, et al. Mesoporous, three-dimensional wood membrane decorated with nanoparticles for highly efficient water treatment. ACS Nano, 2017, 11(4): 4275-4282

40. Fang B, Yang C, Pang C, Shen W, Zhang X, Zhang Y, Yuan W, Liu X. Broadband light absorber based on porous alumina structure covered with ultrathin iridium film. Applied Physics Letters, 2017, 110(14): 141103

41. Zhang L, Xing J, Wen X, Chai J, Wang S, Xiong Q. Plasmonic heating from indium nanoparticles on a floating microporous membrane for enhanced solar seawater desalination. Nanoscale, 2017, 9(35): 12843-12849

42. Ghasemi H, Ni G, Marconnet A M, Loomis J, Yerci S, Miljkovic $\mathrm{N}$, Chen G. Solar steam generation by heat localization. Nature Communications, 2014, 5(1): 4449

43. Yin Z, Wang H, Jian M, Li Y, Xia K, Zhang M, Wang C, Wang Q, Ma M, Zheng Q S, et al. Extremely black vertically aligned carbon nanotube arrays for solar steam generation. ACS Applied Materials \& Interfaces, 2017, 9(34): 28596-28603

44. Selvakumar N, Krupanidhi S B, Barshilia H C. Carbon nanotubebased tandem absorber with tunable spectral selectivity: Transition from near-perfect blackbody absorber to solar selective absorber. Advanced Materials, 2014, 26(16): 2552-2557

45. Wang X, He Y, Cheng G, Shi L, Liu X, Zhu J. Direct vapor generation through localized solar heating via carbon-nanotube nanofluid. Energy Conversion and Management, 2016, 130: 176183

46. Wang Y, Zhang L, Wang P. Self-floating carbon nanotube membrane on macroporous silica substrate for highly efficient solar-driven interfacial water evaporation. ACS Sustainable Chemistry \& Engineering, 2016, 4(3): 1223-1230

47. Ito $\mathrm{Y}$, Tanabe $\mathrm{Y}$, Han J, Fujita T, Tanigaki K, Chen M. Multifunctional porous graphene for high-efficiency steam generation by heat localization. Advanced Materials, 2015, 27(29): 4302-4307

48. Zhang P, Li J, Lv L, Zhao Y, Qu L. Vertically aligned graphene sheets membrane for highly efficient solar thermal generation of clean water. ACS Nano, 2017, 11(5): 5087-5093

49. Yang J, Pang Y, Huang W, Shaw S K, Schiffbauer J, Pillers M A, $\mathrm{Mu} \mathrm{X}$, Luo S, Zhang T, Huang Y, et al. Functionalized graphene enables highly efficient solar thermal steam generation. ACS Nano, 2017, 11(6): 5510-5518

50. Zhang L, Li R, Tang B, Wang P. Solar-thermal conversion and thermal energy storage of graphene foam-based composites. Nanoscale, 2016, 8(30): 14600-14607

51. Li X, Xu W, Tang M, Zhou L, Zhu B, Zhu S, Zhu J. Graphene oxide-based efficient and scalable solar desalination under one sun with a confined 2D water path. Proceedings of the National Academy of Sciences of the United States of America, 2016, 113(49): 13953-13958

52. Jiang Q, Tian L, Liu K K, Tadepalli S, Raliya R, Biswas P, Naik R $\mathrm{R}$, Singamaneni S. Bilayered biofoam for highly efficient solar steam generation. Advanced Materials, 2016, 28(42): 9400-9407

53. Liu K K, Jiang Q, Tadepalli S, Raliya R, Biswas P, Naik R R, Singamaneni $\mathrm{S}$. Wood-graphene oxide composite for highly efficient solar steam generation and desalination. ACS Applied Materials \& Interfaces, 2017, 9(8): 7675-7681

54. Ren H, Tang M, Guan B, Wang K, Yang J, Wang F, Wang M, Shan J, Chen Z, Wei D, et al. Hierarchical graphene foam for efficient omnidirectional solar-thermal energy conversion. Advanced Materials, 2017, 29(38): 1702590

55. Wang Z, Ye Q, Liang X, Xu J, Chang C, Song C, Shang W, Wu J, Tao P, Deng T. Paper-based membranes on silicone floaters for efficient and fast solar-driven interfacial evaporation under one sun. Journal of Materials Chemistry. A, 2017, 5(31): 16359-16368

56. Shi L, Wang Y, Zhang L, Wang P. Rational design of a bi-layered reduced graphene oxide film on polystyrene foam for solar-driven interfacial water evaporation. Journal of Materials Chemistry. A, 2017, 5(31): 16212-16219

57. Wang G, Fu Y, Ma X, Pi W, Liu D, Wang X. Reusable reduced graphene oxide based double-layer system modified by polyethylenimine for solar steam generation. Carbon, 2017, 114: 117124

58. Zhang Y, Zhao D, Yu F, Yang C, Lou J, Liu Y, Chen Y, Wang Z, Tao P, Shang W, et al. Floating RGO-based black membranes for solar driven sterilization. Nanoscale, 2017, 9(48): 19384-19389

59. Liu Y, Chen J, Guo D, Cao M, Jiang L. Floatable, self-cleaning, and carbon-black-based superhydrophobic gauze for the solar evaporation enhancement at the air-water interface. ACS Applied Materials \& Interfaces, 2015, 7(24): 13645-13652

60. Liu Z, Song H, Ji D, Li C, Cheney A, Liu Y, Zhang N, Zeng X, Chen B, Gao J, et al. Extremely cost-effective and efficient solar vapor generation under nonconcentrated illumination using thermally isolated black paper. Global Chall, 2017, 1(2): 1600003

61. Xu N, Hu X, Xu W, Li X, Zhou L, Zhu S, Zhu J. Mushrooms as efficient solar steam-generation devices. Advanced Materials, 2017, 29(28): 1606762

62. Xue G, Liu K, Chen Q, Yang P, Li J, Ding T, Duan J, Qi B, Zhou J. Robust and low-cost flame-treated wood for high-performance solar steam generation. ACS Applied Materials \& Interfaces, 2017, 9(17): 15052-15057

63. Wang J, Liu Z, Dong X, Hsiung C E, Zhu Y, Liu L, Han Y. 
Microporous cokes formed in zeolite catalysts enable efficient solar evaporation. Journal of Materials Chemistry. A, 2017, 5(15): $6860-6865$

64. Liu F, Zhao B, Wu W, Yang H, Ning Y, Lai Y, Bradley R. Low cost, robust, environmentally friendly geopolymer-mesoporous carbon composites for efficient solar powered steam generation. Advanced Functional Materials, 2018, 28(47): 1803266

65. Zhang L, Tang B, Wu J, Li R, Wang P. Hydrophobic light-to-heat conversion membranes with self-healing ability for interfacial solar heating. Advanced Materials, 2015, 27(33): 4889-4894

66. Wu X, Chen G Y, Zhang W, Liu X, Xu H. A plant-transpirationprocess-inspired strategy for highly efficient solar evaporation. Advanced Sustainable Systems, 2017, 1(6): 1700046

67. Huang X, Yu Y H, de Llergo O L, Marquez S M, Cheng Z. Facile polypyrrole thin film coating on polypropylene membrane for efficient solar-driven interfacial water evaporation. RSC Advances, 2017, 7(16): 9495-9499

68. Zhao F, Zhou X, Shi Y, Qian X, Alexander M, Zhao X, Mendez S, Yang R, Qu L, Yu G. Highly efficient solar vapour generation via hierarchically nanostructured gels. Nature Nanotechnology, 2018, 13(6): 489-495

69. Chen Q, Pei Z, Xu Y, Li Z, Yang Y, Wei Y, Ji Y. A durable monolithic polymer foam for efficient solar steam generation. Chemical Science (Cambridge), 2018, 9(3): 623-628

70. Nikitenko S I, Chave T, Cau C, Brau H P, Flaud V. Photothermal hydrogen production using noble-metal-free $\mathrm{Ti} @ \mathrm{TiO}_{2}$ core-shell nanoparticles under visible-NIR light irradiation. ACS Catalysis, 2015, 5(8): 4790-4795

71. Zhou Y, Doronkin D E, Zhao Z, Plessow P N, Jelic J, Detlefs B, Pruessmann T, Studt F, Grunwaldt J D. Photothermal catalysis over nonplasmonic $\mathrm{Pt} / \mathrm{TiO}_{2}$ studied by operando hERFD-XANES, resonant XES, and DRIFTS. ACS Catalysis, 2018, 8(12): 11398 11406

72. Zhao Y, Waterhouse G I N, Chen G, Xiong X, Wu L Z, Tung C H, Zhang T. Two-dimensional-related catalytic materials for solardriven conversion of $\mathrm{CO} x$ into valuable chemical feedstocks. Chemical Society Reviews, 2019, 48(7): 1972-2010

73. Xu C, Huang W, Li Z, Deng B, Zhang Y, Ni M, Cen K. Photothermal coupling factor achieving $\mathrm{CO}_{2}$ reduction based on palladium-nanoparticle-loaded $\mathrm{TiO}_{2}$. ACS Catalysis, 2018, 8(7): 6582-6593

74. Li R, Zhang L, Shi L, Wang P. Mxene $\mathrm{Ti}_{3} \mathrm{C}_{2}$ : An effective $2 \mathrm{D}$ lightto-heat conversion material. ACS Nano, 2017, 11(4): 3752-3759

75. Zhu G, Xu J, Zhao W, Huang F. Constructing black titania with unique nanocage structure for solar desalination. ACS Applied Materials \& Interfaces, 2016, 8(46): 31716-31721

76. Wang J, Li Y, Deng L, Wei N, Weng Y, Dong S, Qi D, Qiu J, Chen $\mathrm{X}, \mathrm{Wu} \mathrm{T}$. High-performance photothermal conversion of narrowbandgap $\mathrm{Ti}_{2} \mathrm{O}_{3}$ nanoparticles. Advanced Materials, 2017, 29(3): 1603730

77. Ye M, Jia J, Wu Z, Qian C, Chen R, O'Brien P G, Sun W, Dong Y, Ozin G A. Synthesis of black tioxnanoparticles by mg reduction of $\mathrm{TiO}_{2}$ nanocrystals and their application for solar water evaporation. Advanced Energy Materials, 2017, 7(4): 1601811

78. Ding D, Huang W, Song C, Yan M, Guo C, Liu S. Nonstoichiometric $\mathrm{MoO}_{3-x}$ quantum dots as a light-harvesting material for interfacial water evaporation. Chemical Communications, 2017, 53(50): 6744-6747

79. Hu X, Xu W, Zhou L, Tan Y, Wang Y, Zhu S, Zhu J. Tailoring graphene oxide-based aerogels for efficient solar steam generation under one sun. Advanced Materials, 2017, 29(5): 1604031

80. Sharma B, Rabinal M K. Plasmon based metal-graphene nanocomposites for effective solar vaporization. Journal of Alloys and Compounds, 2017, 690: 57-62

81. Fu Y, Mei T, Wang G, Guo A, Dai G, Wang S, Wang J, Li J, Wang $\mathrm{X}$. Investigation on enhancing effects of Au nanoparticles on solar steam generation in graphene oxide nanofluids. Applied Thermal Engineering, 2017, 114: 961-968

82. Yang X, Yang Y, Fu L, Zou M, Li Z, Cao A, Yuan Q. An ultrathin flexible 2D membrane based on single-walled nanotube- $\mathrm{MoS}_{2}$ hybrid film for high-performance solar steam generation. Advanced Functional Materials, 2018, 28(3): 1704505

83. Wang Y C, Wang C Z, Song X J, Megarajan S K, Jiang H Q. A facile nanocomposite strategy to fabricate a rGO-MWCNT photothermal layer for efficient water evaporation. Journal of Materials Chemistry. A, 2018, 6(3): 963-971

84. Yang Y, Yang X, Fu L, Zou M, Cao A, Du Y, Yuan Q, Yan C H. Two-dimensional flexible bilayer janus membrane for advanced photothermal water desalination. ACS Energy Letters, 2018, 3(5): 1165-1171

85. Taylor R A, Phelan P E, Adrian R J, Gunawan A, Otanicar T P. Characterization of light-induced, volumetric steam generation in nanofluids. International Journal of Thermal Sciences, 2012, 56: 111

86. Lenert A, Wang E N. Optimization of nanofluid volumetric receivers for solar thermal energy conversion. Solar Energy, 2012, 86(1): 253-265

87. Ni G, Miljkovic N, Ghasemi H, Huang X, Boriskina S V, Lin C T, Wang J, Xu Y, Rahman M M, Zhang T, et al. Volumetric solar heating of nanofluids for direct vapor generation. Nano Energy, 2015, 17: 290-301

88. Liu Z, Yang Z, Huang X, Xuan C, Xie J, Fu H, Wu Q, Zhang J, Zhou X, Liu Y. High-absorption recyclable photothermal membranes used in a bionic system for high-efficiency solar desalination via enhanced localized heating. Journal of Materials Chemistry. A, 2017, 5(37): 20044-20052

89. Lou J, Liu Y, Wang Z, Zhao D, Song C, Wu J, Dasgupta N, Zhang $\mathrm{W}$, Zhang D, Tao $\mathrm{P}$, et al. Bioinspired multifunctional paper-based rGO composites for solar-driven clean water generation. ACS Applied Materials \& Interfaces, 2016, 8(23): 14628-14636

90. Yang P, Liu K, Chen Q, Li J, Duan J, Xue G, Xu Z, Xie W, Zhou J. Solar-driven simultaneous steam production and electricity generation from salinity. Energy \& Environmental Science, 2017, 10(9): 1923-1927

91. Chen C, Li Y, Song J, Yang Z, Kuang Y, Hitz E, Jia C, Gong A, Jiang F, Zhu J Y, et al. Highly flexible and efficient solar steam generation device. Advanced Materials, 2017, 29(30): 1701756

92. Ni G, Li G, Boriskina S V, Li H, Yang W, Zhang T, Chen G. Steam generation under one sun enabled by a floating structure with thermal concentration. Nature Energy, 2016, 1(9): 16126

93. Zhu M, Li Y, Chen F, Zhu X, Dai J, Li Y, Yang Z, Yan X, Song J, Wang $\mathrm{Y}$, et al. Plasmonic wood for high-efficiency solar steam 
generation. Advanced Energy Materials, 2018, 8(4): 1701028

94. Li X, Lin R, Ni G, Xu N, Hu X, Zhu B, Lv G, Li J, Zhu S, Zhu J. Three-dimensional artificial transpiration for efficient solar wastewater treatment. National Science Review, 2018, 5(1): 70-77

95. Wang Y, Wang C, Song X, Huang M, Megarajan S K, Shaukat S F, Jiang H. Improved light-harvesting and thermal management for efficient solar-driven water evaporation using 3D photothermal cones. Journal of Materials Chemistry. A, 2018, 6(21): 98749881

96. Ni G, Zandavi S H, Javid S M, Boriskina S V, Cooper T A, Chen G. A salt-rejecting floating solar still for low-cost desalination. Energy \& Environmental Science, 2018, 11(6): 1510-1519

97. Zhuang S, Zhou L, Xu W, Xu N, Hu X, Li X, Lv G, Zheng Q, Zhu $\mathrm{S}$, Wang $\mathrm{Z}$, et al. Tuning transpiration by interfacial solar absorberleaf engineering. Advancement of Science, 2018, 5(2): 1700497

98. Morciano M, Fasano M, Salomov U, Ventola L, Chiavazzo E, Asinari P. Efficient steam generation by inexpensive narrow gap evaporation device for solar applications. Scientific Reports, 2017, 7(1): 11970

99. Xue G, Chen Q, Lin S, Duan J, Yang P, Liu K, Li J, Zhou J. Highly efficient water harvesting with optimized solar thermal membrane distillation device. Global Challenges, 2018, 2(5-6): 1800001
100. Canbazoglu F M, Fan B, Kargar A, Vemuri K, Bandaru P R. Enhanced solar evaporation of water from porous media, through capillary mediated forces and surface treatment. AIP Advances, 2016, 6(8): 085218

101. Huang Z, Li X, Yuan H, Feng Y, Zhang X. Hydrophobically modified nanoparticle suspensions to enhance water evaporation rate. Applied Physics Letters, 2016, 109(16): 161602

102. Zeng Y, Wang K, Yao J, Wang H. Hollow carbon beads for significant water evaporation enhancement. Chemical Engineering Science, 2014, 116: 704-709

103. Cui L, Zhang P, Xiao Y, Liang Y, Liang H, Cheng Z, Qu L. High rate production of clean water based on the combined photoelectro-thermal effect of graphene architecture. Advanced Materials, 2018, 30(22): 1706805

104. Zhu L, Gao M, Peh C K N, Wang X, Ho G W. Self-contained monolithic carbon sponges for solar-driven interfacial water evaporation distillation and electricity generation. Advanced Energy Materials, 2018, 8(16): 1702149

105. Wang P. Emerging investigator series: The rise of nano-enabled photothermal materials for water evaporation and clean water production by sunlight. Environmental Science: Nano, 2018, 5(5): 1078-1089 